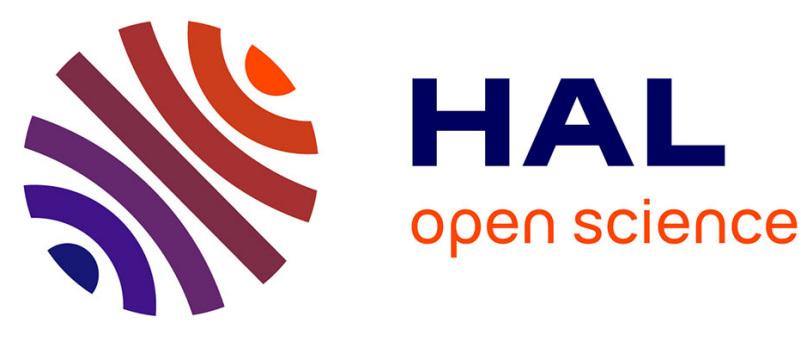

\title{
Earth's Energy Imbalance Measured From Space
}

Maria Z. Hakuba, Graeme L. Stephens, Bruno Christophe, Alfred E. Nash, Bernard Foulon, Srinivas V. Bettadpur, Byron D. Tapley, Frank H. Webb

\section{To cite this version:}

Maria Z. Hakuba, Graeme L. Stephens, Bruno Christophe, Alfred E. Nash, Bernard Foulon, et al.. Earth's Energy Imbalance Measured From Space. IEEE Transactions on Geoscience and Remote Sensing, In press, 10.1109/TGRS.2018.2851976 . hal-01870008

\section{HAL Id: hal-01870008 https://hal.science/hal-01870008}

Submitted on 7 Sep 2018

HAL is a multi-disciplinary open access archive for the deposit and dissemination of scientific research documents, whether they are published or not. The documents may come from teaching and research institutions in France or abroad, or from public or private research centers.
L'archive ouverte pluridisciplinaire $\mathbf{H A L}$, est destinée au dépôt et à la diffusion de documents scientifiques de niveau recherche, publiés ou non, émanant des établissements d'enseignement et de recherche français ou étrangers, des laboratoires publics ou privés. 


\title{
Earth's Energy Imbalance measured from Space
}

\author{
Maria Z. Hakuba, Graeme L. Stephens, Bruno Christophe, Alfred E. Nash, Bernard Foulon, Srinivas \\ V. Bettadpur, Byron D. Tapley, Frank H. Webb
}

\begin{abstract}
The direct measurement of Earth's energy imbalance (EEI) is one of the greatest challenges in climate research. The global mean EEI represents the integrated value of global warming and is tightly linked to changes in hydrological cycle and the habitability of our planet. Current space-born radiometers measure the individual radiative components of the energy balance with unprecedented stability, but with calibration errors too large to determine the absolute magnitude of global mean EEI as the components' residual. Best estimates of long-term EEI are currently derived from temporal changes in ocean heat content at $\sim 0.7 \mathrm{Wm}^{-2}$. To monitor EEI directly from space, we propose an independent approach based on accelerometry that measures nongravitational forces, such as radiation pressure, acting on Earth orbiting spacecrafts. The concept of deriving EEI from radiation pressure has been considered in the past, and we provide analysis that shows today's capabilities are sufficiently accurate to answer the question: At what rate is our planet warming? To measure global mean EEI to within at least $\pm 0.3 \mathrm{Wm}^{-2}$ requires spacecraft(s) of near-spherical shape and well-characterized surface properties to reduce confounding effects. The proposed concept may provide the basis for a data record of global and zonal mean EEI on annual and potentially monthly time scales. It is not meant to replace existing concepts designed to measure energy balance components or ocean heat storage, but to complement these by providing an independent estimate of EEI for comparison and to anchor data products and climate models that lack energy balance closure.
\end{abstract}

Index Terms-Low Earth orbit satellites, Global warming, Remote sensing, Earth's energy imbalance, Accelerometer

\section{BACKGROUND}

THE Earth's global mean energy imbalance (EEI) and its temporal variability is the most direct measure of the magnitude and change of global warming [1][2][3]. Presently, two predominant ways are pursued to estimate the build-up of heat in our climate system. The first deduces the imbalance as a residual of the sum of the individual fluxes of incoming and outgoing shortwave and longwave radiation at the top-of-theatmosphere (TOA). The second approach infers the EEI as the temporal change in ocean heat content derived either from insitu profiles of ocean temperature, such as measured by Argo's

This work was supported in part by the U.S. Department of Commerce under Grant BS123456."

Maria Z. Hakuba is with Colorado State University, Ft Collins, CO 80523 USA and Jet Propulsion Laboratory, California Institute of Technology, Pasadena, CA 91109 USA (e-mail: maria.z.hakuba@jpl.nasa.gov).

Graeme L. Stephens is with Jet Propulsion Laboratory, California Institute of Technology, Pasadena, CA 91109 USA (email: graeme.stephens@jpl.nasa.gov).

B. Christophe is with DPHY, ONERA, Université Paris Saclay, F-92322 Châtillon - France (e-mail: bruno.christophe@onera.fr). automated floats [4][5], from ocean modeling and reanalysis [6][7], or from combinations of remote sensing techniques [8] [9].

Ninety-three percent of the excess heat due to global warming is stored in the world's oceans [10], buffering the temperature increase at Earth's land surface and atmosphere. The retrieval of ocean heat storage (i.e. temporal change in ocean heat content) from Argo and historical in-situ measurements $[11][12]$ is considered the most reliable source for global mean EEI over the past decades [10][13][14], ranging between 0.5 $0.9 \mathrm{Wm}^{-2}$ (e.g. [15][16][11][17][18][19]).

The most reliable measurement of the radiative components of Earth's energy balance at TOA are provided by the Clouds and the Earth's Radiant Energy System (CERES [20]). The radiometric monitoring of the shortwave and longwave fluxes is achieved within error bounds an order of magnitude larger than the estimated global mean EEI [21][22]. Due to mainly calibration errors, the long-term (2005-2015) global mean EEI derived from CERES data is at about $+4 \mathrm{Wm}^{-2}[23][24]$ almost ten times greater than the ocean heat storage estimates from ocean in-situ measurements (see above). CERES provides an energy balanced data product (EBAF), in which the global multiannual mean fluxes are adjusted within their range of uncertainty to agree with the global long-term mean ocean heat storage [23]. This adjusted, energy-balanced data product is widely used by the community despite the lack of absolute accuracy. Although anchored to the long-term mean of global ocean heat storage, the interannual variability in CERES's EEI is independent of the ocean data and known to within $\pm 0.3 \mathrm{Wm}^{-}$ 2 [23]. Information on temporal variability in global mean ocean heat storage from Argo is limited to decadal scale averages within about $\pm 0.1 \mathrm{Wm}^{-2}[1][25]$ due to presumably sampling caveats. The Argo system's spatial coverage varies over time, does not capture the deep ocean below 2000 meters, and under samples polar oceans and marginal seas. Consequently, the interannual variability derived from Argo is somewhat noisy and disagrees with the CERES EBAF record [2][26][27] as also demonstrated in Figure 1 (see section II).

In addition to the in-situ profiling of ocean temperature, there are two other ways to estimate the ocean heat content: ocean

A. E. Nash is with Jet Propulsion Laboratory, California Institute of Technology, Pasadena, CA 91109 USA (email: Alfred.E.Nash@jpl.nasa.gov). B. Foulon is with DPHY, ONERA, Université Paris Saclay, F-92322

Châtillon - France (e-mail: bernard.foulon@onera.fr).

S. V. Bettadpur is with University of Texas at Austin, Austin, TX 78712 USA. (email: srinivas@csr.utexas.edu).

B. D. Tapley is with University of Texas at Austin, Austin, TX 78712 USA. (email: tapley@csr.utexas.edu).

F. H. Webb is with Jet Propulsion Laboratory, California Institute of Technology, Pasadena, CA 91109 USA (email: frank.h.webb@jpl.nasa.gov). 
reanalysis/models that augment the horizontal and vertical coverage [6][7], and remote sensing of ocean mass and sea level height [9][28]. A combination of such datasets, as for example originating from GRACE (ocean mass [29]) and JASON (ocean altimetry [30]), permits an estimate of global mean thermosteric sea level rise and therefore the thermal expansion of the oceans due to heat uptake. Recent literature suggests that this retrieval of global mean ocean heat storage is possible with an absolute accuracy superior to the broadband radiometry approach, whereby the magnitude and source of error are yet subjects of research (e.g., [31][32][33][34]).

To date, the only way to estimate the absolute magnitude of long-term global mean EEI is via in-situ sampling or remote sensing of ocean heat storage, while the radiometric measurement provides the most viable means to monitor temporal changes in EEI. Although complementing each other, these independent approaches do not allow for intercomparison and validation. Therefore, unknown biases and uncertainties in either method cannot be precluded.

Here, we present an independent approach to directly measure EEI from space that is based on the principle of measuring radiation pressure force exerted on Earth orbiting spacecrafts. The trajectory of the spacecraft(s) draws a "virtual" sphere around the Earth at orbit altitude. The objective of the mission is to obtain the net radiative flux through this sphere, through measuring the radial component of the radiation pressure acceleration the spacecraft is subjected to. This measurement has the potential to achieve an absolute accuracy well beyond what can be achieved by radiometry. Therefore, we conceive it to be an adjunct to the radiometric measurements that provide essential information about the radiative components and associated feedbacks, but cannot provide a direct measure of global mean EEI. To fill this gap, the foremost goal of the proposed concept is to provide the integrated value of global mean EEI at annual time scales. This independent estimate of the absolute magnitude of EEI can be used to anchor other datasets, such as from radiometry or climate modeling [35][36], that lack energy balance closure. The secondary goal is to obtain monthly and zonal averages, providing the means to track large-scale heat transports across latitudes over seasonal and interannual timescales, and to conduct valuable inter comparisons with other independent EEI estimates originating from radiometry, ocean heat uptake, and reanalysis.

In this concept, an accelerometer on board a small satellite, as widely employed to estimate non-gravitational forces in orbit, is considered a wide field-of-view (WFOV) sensor. The spacecraft's skin coating represents the sensitive area by which the radiation fluxes are transformed into forces and accelerations. It should be noted that this relatively simple technique has some important limitations, since little information can be provided on the spectral distribution, space and time resolution, and the individual radiative flux components. Deriving the radiative components from the radiation pressure approach is not per se impossible, but will not be discussed here.

On satellite systems that aim at measuring very small fluctuations in Earth's gravity field at high accuracy such as GRACE or GOCE [37], ultra-sensitive accelerometers are used to quantify and eliminate the impact of non-gravitational forces such as those exerted by radiation pressure or atmospheric drag. By minimizing the non-gravitational forces other than radiation pressure through an optimal mission design, the EEI is in principle derivable within established accuracy requirements. The feasibility of this concept has been demonstrated in the past with measurements performed by the CACTUS accelerometer on CASTOR in 1975 (e.g.,[38]). A second ESA project, BIRAMIS, facilitated the study of a more optimized system as well as the evaluation of its error budget [39][40]. Today, the instrument accuracy and satellite design capabilities have much improved, paving the way for a successful mission.

This paper represents a first step towards a potential mission design for measuring the EEI directly from space. We revisit the measurement of radiation pressure and examine whether current measurement capability provides the accuracy and precision to estimate the global and regional mean EEI at TOA to at least within $\pm 0.3 \mathrm{Wm}^{-2}$ (see section IV). In section II we describe the spatial and temporal nature of EEI as we understand it from analysis of CERES EBAF data. Section III outlines the theoretical framework of the EEI derived from radiation pressure measurements. In sections IV and $\mathrm{V}$, we present and quantify to the extent possible instrument requirements and impacts of perturbing forces. A brief summary of early results based on CACTUS measurements is provided to demonstrate the overall feasibility of this approach in section VI. Sections VII and VIII concern the instrument and potential spacecraft characteristics. We briefly discuss potential orbit and sampling considerations in section IX and conclude with a summary of remaining challenges in section $\mathrm{X}$.

\section{TEMPORAL AND SPATIAL NATURE OF EEI}

The concept presented here predominantly aims at the measurement of long-term global mean EEI, but we briefly discuss aspects of spatial and temporal variability to provide first-order accuracy and sampling requirements. Although beyond the scope of this paper, temporal and spatial sampling considerations are crucial for the best possible estimate of annual global mean EEI (see also section IX).

Figure 1 shows a time series of monthly anomalies (gray) and the 12-month running mean (purple) of EEI between March 2000 to January 2017 based on CERES EBAF edition 4.0 (https://ceres-tool.larc.nasa.gov/ord-tool/jsp/EBAF4Selection. jsp).

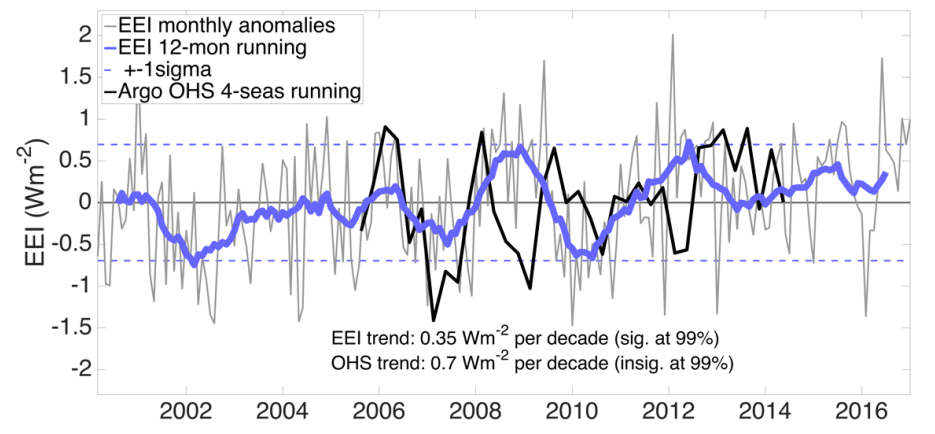

Figure 1: Global mean EEI (CERES EBAF edition 4.0) in terms of monthly anomalies (gray) and 12-months running means (purple) together with $\pm 1 \sigma$ ranges and Argo-based ocean heat storage (OHS) estimates in terms of four seasons running means of seasonal anomalies (black). 
The anomalies reflect the internal variability of the climate system, predominantly that of ENSO, dipping significantly in response to the 2007 and 2009 El Niño events, and peaking in La Niña periods $(2008,2012)$. The range of interannual variability is at $0.7 \mathrm{Wm}^{-2}(1 \sigma)$ and of the same order as the longterm mean of EEI $\left(0.7 \pm 0.1 \mathrm{Wm}^{-2}\right)$ to which the data product has been adjusted [25]. A significant trend at $0.4 \mathrm{Wm}^{-2}$ per decade is observed over 2001-2015. To detect a trend of that order with $20 \%$ uncertainty would take about 18 years using a perfect observing system with no measurement uncertainty. Adding a measurement uncertainty at $0.3 \mathrm{Wm}^{-2}$ (see section IV) increases the detection time beyond 38 years. These detection times were estimated using EEI monthly anomalies and the trend time detection formulae after [41]. From this we take, that trends in EEI may not be detectable within the scope of a typical mission lifetime of three to ten years, but the interannual $\left(\sigma=0.7 \mathrm{Wm}^{-2}\right)$ and seasonal variability of global mean EEI $\left(\sigma=7 \mathrm{Wm}^{-2}\right)$, as well as the zonal variability of multi-annual means $\left(\sigma=64 \mathrm{Wm}^{-}\right.$ ${ }^{2}$ ) are detectable at a measurement accuracy better than $0.7 \mathrm{Wm}^{-}$ 2 .

The black line in Figure 1 represents the timeseries of global mean ocean heat storage (OHS) calculated from the average ocean heat content of three Argo-based datasets as computed by [18] in terms of running means of four seasonal anomalies.
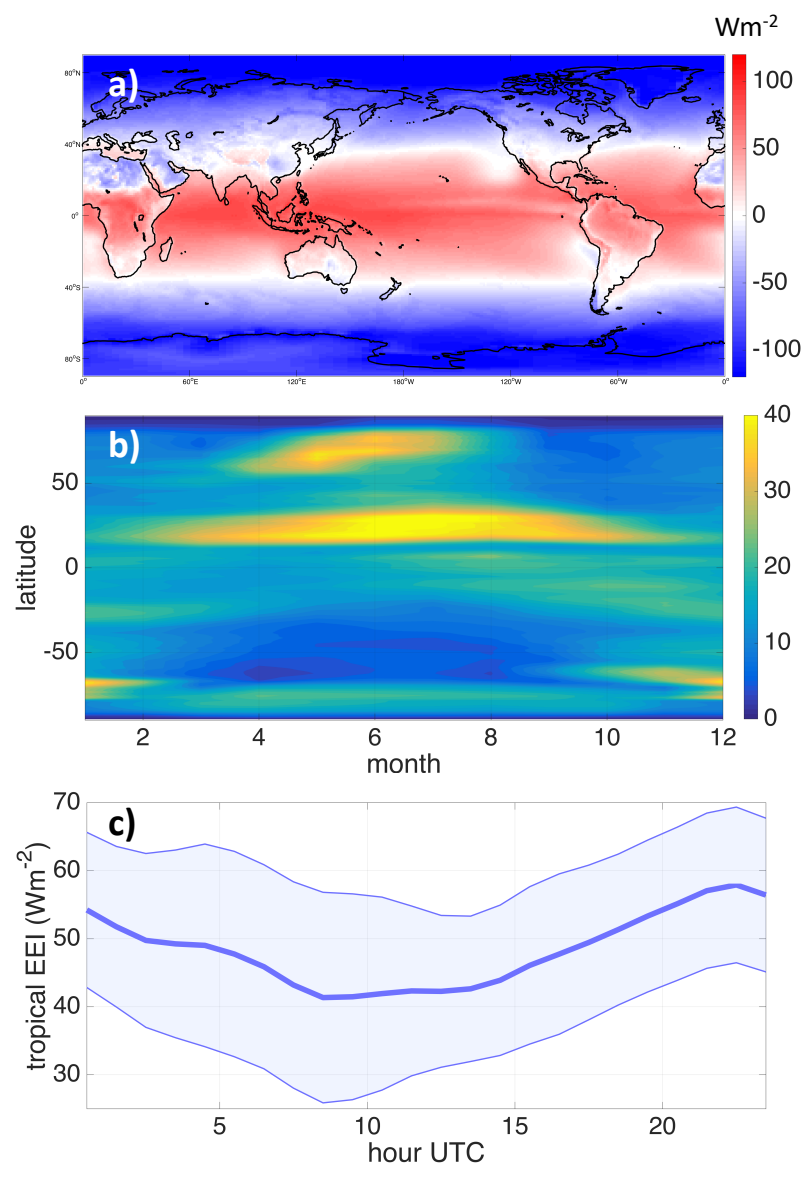

Figure 2: a) Annual mean (2000-2017) net radiative flux at TOA (CERES EBAF) and b) the annual cycle of zonal standard deviation of net flux and c) tropical $\left(30^{\circ} \mathrm{S}-30^{\circ} \mathrm{N}\right)$ annual mean (2016) diurnal cycle (CERES SYN1deg).
Although this averaging strongly reduces the amplitude and noise in the seasonal anomalies $\left(\sigma>2 \mathrm{Wm}^{-2}\right)$, the interannual variability substantially disagrees with the EEI estimates from CERES EBAF, presumably a result of sampling errors (see Section I). Figure 2a is a global map of the multi-annual mean EEI (2000-2017). On average, the EEI is positive in the tropics and negative over the poles with near zero values at the mid latitudes. Being the sum of incoming solar radiation, reflected solar radiation, and Earth's thermal emission, we expect a positive net radiative flux to induce a net "inward" acceleration on the spacecraft when at lower latitudes, and a net "outward" acceleration at higher latitudes. Figure $2 b$ shows the climatological mean standard deviation within each zonal band per month. The largest spatial variability in EEI is found between $10^{\circ}$ to $30^{\circ}$ North throughout the year and related to the variable surface reflectivity of the oceans and bright desert areas encompassed by these zones. High values are also seen at higher latitudes on both hemispheres during respective summer seasons, a result of variable insolation and surface properties of the polar regions (ice-free ocean versus ice/snow covered ocean and land). This gives some idea on where frequent observations are preferable to cover the spatial variability of climatological mean EEI.

Figure 2c shows the annual mean (2016) diurnal cycle of EEI averaged over the tropical band $\left(30^{\circ} \mathrm{S}-30^{\circ} \mathrm{N}\right)$ derived from CERES

SYN1deg data (https://ceres.larc.nasa.gov/products.php?product=SYN1deg). This dataset uses information from geostationary satellites to incorporate diurnal variability and reduce spatial sampling errors [42]. In this zonal band, the EEI varies in concert with longwave and shortwave outgoing fluxes, which peak around noon and 9 am (UTC), respectively. The shading indicates the seasonal scatter in terms of $\pm 1 \sigma$. Naturally, the annual mean diurnal cycle of the tropics is smoothed out by the zonal and annual averaging, but is in essence what the concept proposed here should aim to capture.

The estimates derived here represent first order requirements for detecting and sampling EEI spatial and temporal variability; the discussion of requirements for measurement accuracy will be refined in section IV.

\section{THEORY}

\section{A. Radiation pressure force}

The effect of radiation pressure on artificial satellites has been studied extensively since the onset of space exploration (e.g., $[43][44][45])$. Here, we provide the theoretical basis that connects radiation pressure measurements to the EEI based in part on [46]. From the Einstein mass-energy conservation principle follows the equivalence between photon energy and momentum. Therefore, when a photon impinges on an object and is either reflected or absorbed, its momentum is removed and conveyed to the object, resulting in a radiation pressure force that induces an acceleration of the object, i.e. spacecraft. This acceleration can be measured by an accelerometer of sufficient sensitivity situated in the center of the spacecraft.

The radiation pressure vector force $\vec{P}$ exerted on an object of mass $m$ is a function of the spectral radiative flux $\vec{F}(\lambda)$, the 
speed of light $c$, and the effective extinction cross-section $C_{\text {ext }}$ that depends on the actual cross-section of the object, the thermo-optical properties of the object surface, the flux wavelength $(\lambda)$ and the flux incident angle $(\theta)$.

$$
\vec{P}=m \vec{a}=\frac{1}{c} C_{\text {ext }}(\lambda, \theta) \vec{F}(\lambda)
$$

For the acceleration vector $(\vec{a})$ due to radiation pressure $\vec{P}$ follows from (1)

$$
\vec{a}=\frac{C_{\text {ext }}(\lambda, \theta)}{m} \frac{\vec{F}(\lambda)}{c}
$$

Since the two-dimensional tensor $C_{\text {ext }}(\lambda, \theta)$ can change the direction of $\vec{P}$ with respect to $\vec{F}(\lambda)$, the acceleration $\vec{a}$ is not necessarily co-linear with the direction of $\vec{F}(\lambda)$ unless the incident angle $(\theta)$ and spectral $(\lambda)$ dependence are eliminated. This can be achieved by considering a spherical object (independent of $\theta$ ) whose surface's thermo-optical properties are independent of $\lambda$. [46][47]. The co-linearity between $\vec{F}(\lambda)$ and $\vec{a}$ is a prerequisite for the derivation of EEI from radiation pressure force $\vec{P}$ (see section $B$ ).

Under the assumption of no spectral dependence and considering a spherical object with radius $r$, the effective crosssection can be defined as follows. The object coating's thermooptical properties are distinguished between the coating's absorptivity (A), total reflectivity $\mathrm{R}$, specular reflectivity $\mathrm{R}_{\mathrm{s}}$, diffuse reflectivity $\mathrm{R}_{\mathrm{D}}$, transmissivity $\mathrm{T}$ (here $=0$ ), and emissivity $(\varepsilon)$, whereby $A+R=1, R_{S}+R_{D}=R, \varepsilon \leq A$.

According to [46] it follows for the absorption cross-section: $\sigma_{A}=A \pi r^{2}$, the specular cross-section: $\sigma_{R_{S}}=R_{S} \pi r^{2}$, the diffuse reflective cross-section: $\sigma_{R_{D}}=R_{D} \frac{4}{3} \pi r^{2}$, and the diffuse emission cross-section: $\sigma_{\varepsilon}=\varepsilon \frac{1}{3} \pi r^{2}$, which represents a parasitic term. The total effective cross-section of an absorbing-reflecting spherical object is then:

$$
\begin{gathered}
C_{\text {ext }}=\sigma=\pi r^{2}\left(A+R_{S}+R_{D}+\frac{R_{D}}{3}\right) \\
=\pi r^{2}\left(1+\frac{R_{D}}{3}\right) \\
=\Sigma * K
\end{gathered}
$$

where $\Sigma$ is the actual geometric cross-section $\pi r^{2}$ and $\mathrm{K}$ is the coating property coefficient, under the assumption of no

TABLE I

REQUIREMENTS

\begin{tabular}{lll}
\hline \hline Flux & $\begin{array}{c}\text { GLOBAL MEAN }\left(\mathrm{WM}^{-2}\right) \\
\pm \text { UNCERTAINTY }\end{array}$ & $\begin{array}{l}\text { derived acceleration }\left(\mathrm{ms}^{-2}\right) \\
\pm \text { uncertainty }\end{array}$ \\
\hline ISR & $340 \mathrm{Wm}^{-2} \pm 0.01 \%$ & $1.8 \cdot 10^{-8} \pm 1.8 \cdot 10^{-12}$ \\
RSR & $100 \mathrm{Wm}^{-2} \pm 0.3 \%$ & $5.3 \cdot 10^{-9} \pm 1.6 \cdot 10^{-11}$ \\
IR & $240 \mathrm{Wm}^{-2} \pm 0.9 \%$ & $1.3 \cdot 10^{-8} \pm 1.1 \cdot 10^{-10}$ \\
EEI & $\sim 0.7 \mathrm{Wm}^{-2} \pm 0.4 \mathrm{Wm}^{-2}$ & $3.7 \cdot 10^{-11} \pm 2.1 \cdot 10^{-11}$ \\
EEI & $\sim 0.7 \mathrm{Wm}^{-2} \pm 0.1 \mathrm{Wm}^{-2}$ & $3.7 \cdot 10^{-11} \pm 0.5 \cdot 10^{-11}$
\end{tabular}

$\mathrm{a}_{\mathrm{R}}=\frac{1}{c} F * \frac{\Sigma * K}{\mathrm{~m}}$ with $\mathrm{F}=$ radiative flux, $\Sigma=$ actual cross-section $\pi r^{2}, \mathrm{r}=0.5 \mathrm{~m}$, $\mathrm{K}=1$ (perfectly absorbing), $\mathrm{m}=50 \mathrm{~kg}, \mathrm{c}=$ speed of light spectral dependence. $\mathrm{K}$ equals 1 if the object is either perfectly absorbing or specular reflecting.

Considering the net radiative flux as the sum of the solar, lunar and terrestrial sources, there will be non-zero acceleration of the spherical object along the $\mathrm{x}, \mathrm{y}$, and $\mathrm{z}$ components in threedimensional space. The sum of these acceleration components yields the effective net radiation pressure induced acceleration $\vec{a}_{n e t}$ co-linear with the direction of incident net radiative flux $\vec{F}$. In a rotated coordinate system where the $\mathrm{z}$ vector component of $\vec{a}_{n e t}$ is along the radial axis from the Earth's center, a spherical spacecraft will undergo an acceleration in the radial direction

$$
\vec{a}_{r}=\vec{F}_{r} * \frac{\Sigma * K}{\mathrm{~m} * \mathrm{c}}
$$

where $\vec{F}_{r}$ is the net radiative flux along the radial direction normal to a horizontal surface at the spacecraft location [46]. Needless to say, this only holds in an environment in which other non-gravitational forces are either held constant or are negligibly small (see section $V$ ).

\section{B. From acceleration to flux}

The global mean EEI at the TOA represents the net radiative flux through a sphere around Earth, provided the observing system's orbit is circular. The surface flux through this sphere is independent of the direction of the net radiative flux, only the radial component of the net radiative flux contributes to the sphere's surface flux.

More specifically, EEI is the surface integral of the net radiative flux component normal to the horizontal surface at the TOA, where the net radiative flux is the sum of incoming solar radiation, reflected solar radiation, and the Earth's emitted thermal radiation. The geometry of the relation between the net radiative flux on a horizontal surface (TOA) and the radial acceleration that it induces is highlighted in Figure 3. The net radiative flux through some horizontal surface element $d S$ at the TOA is $F \cdot n$ (schematically represented by the green arrows), where $n$ is the surface normal and $F$ is the constant net radiative flux vector field (yellow arrows). This means, the net 'surface' flux through the TOA (location of spacecraft) can be derived from $F \cdot n$ solely, and knowledge of the direction of $F$ is

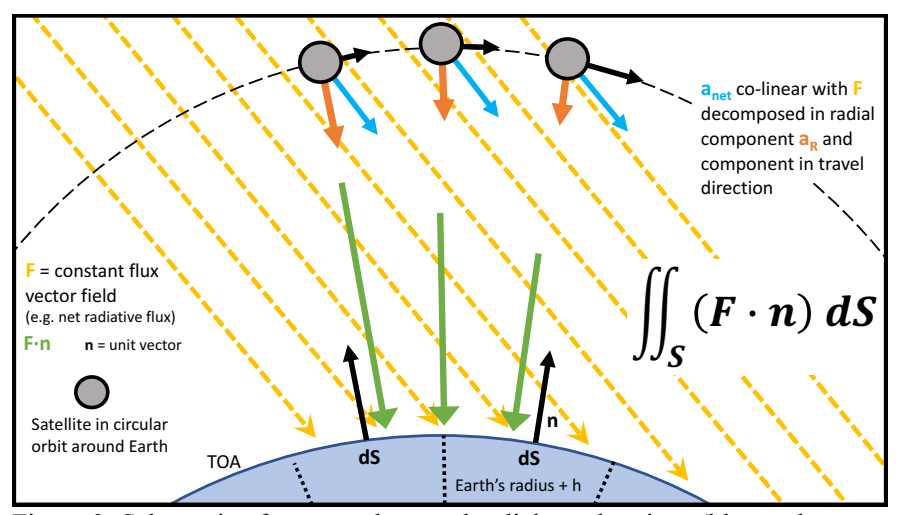

Figure 3: Schematic of measured net and radial accelerations (blue and orange arrows) induced by constant flux vector field (yellow). 
redundant. If $F$ induces an acceleration anet (black arrows) that is co-linear to its direction, $F \cdot n$ (or $F_{r}$, see previous section) is associated with an acceleration along the radial direction $a_{R}$ (orange arrows), the radial component of anet. Therefore, to facilitate EEI observations via accurate measurements of $\mathrm{a}_{\mathrm{R}}$, the induced accelerations $a_{\text {net }}$ have to be co-linear to the impinging net irradiances. This only holds, if we assume a spacecraft of spherical shape, which also avoids polarization effects [48], and with constant near-perfect absorbing or reflecting coating properties $(\mathrm{K}=1)$ that are independent of wavelength and incident angle. Different coating materials that yield property coefficients (K) near 1 have been assessed in the wake of BIRAMIS related studies [48], and are briefly summarized in section VIII.

The definition of the net 'surface' flux through TOA and its relation to measurable radial accelerations induced by $F \cdot n$, facilitate the direct measurement of EEI, and help to eliminate the perturbing effect of atmospheric drag (see section V.) While this theoretical framework is appealing, the measurement of radiation flux via radiation pressure is an intricate multi-part problem and requires high instrument sensitivity and optimal spacecraft design as a first prerequisite. The accelerometer MicroSTAR developed at ONERA, France, fulfills the requirements of accuracy and stability and is presented in section VII together with planned calibration procedures. Second, the vector field $F$ is not constant and varies with time and location, as does its normal component $F \cdot n$. Therefore, further study is needed to determine the measurement accuracy of the radial acceleration as a function of time and position, and in dependence of different illumination angles, synoptic weather patterns, and spacecraft characteristics. Third, the removal of parasitic forces or confounding variables, respectively, is crucial to isolate the accelerations due to radiation pressure. This can be done by either minimizing their impact by certain geometric and orbital design considerations or by modeling. Some of the leading confounding variables and their average magnitude are presented in section $V$. Fourth, from the perspective of mission design, spatio-temporal sampling considerations will shape the orbital configuration in which one or multiple spacecrafts are foreseen to provide global mean estimates of EEI within acceptable error bounds derived in Section IV. The quest for such an optimal configuration is subject of future research and briefly discussed in Section IX. Fifth, to obtain a climate data record instrumental in radiation budget studies, temporal and spatial interpolation schemes and flux deconvolution to an optimal TOA level ( 20km [49]) are essential and subject of future study. These design and processing steps will eventually provide the basis for a higherlevel product of global and zonal mean EEI on monthly and annual time scales.

For the remainder of the paper, when we derive requirements (section IV) and the average magnitude of confounding effects (section V), we refer to a spherical satellite with $K=1$, mass $=50 \mathrm{~kg}$ and $\mathrm{r}=0.5 \mathrm{~m}$. The orbit height we set to $1300 \mathrm{~km}$, an altitude well below the Van Allen belts at which the impact of aerodynamic drag is minimized, and potentially a "sweet spot" for the spatio-temporal sampling via multiple spacecrafts (section IX).

\section{REQUIREMENTS}

Accuracy requirements for the radiative flux components of the energy balance have been established by the community [50][51] and WMO's Global climate observing system [52]. It follows that observing systems are required to measure incoming solar radiation (ISR) within $\pm 0.01 \%\left(\sim 0.034 \mathrm{Wm}^{-2}\right)$ of the global annual mean $\left(\sim 340 \mathrm{Wm}^{-2}\right)$, the reflected solar flux (RSR) within $\pm 0.3 \%\left(\sim 0.3 \mathrm{Wm}^{-2}\right.$, global annual mean at $\sim 100$ $\mathrm{Wm}^{-2}$ ), and the Earth emitted thermal radiation (IR) at $\pm 0.1 \%$ $\left(\sim 0.24 \mathrm{Wm}^{-2}\right.$, global annual mean at $\left.\sim 240 \mathrm{Wm}^{-2}\right)$, in order to enable meaningful interpretation. None of these sources define directly an uncertainty requirement for the EEI, but an error expansion yields $\pm 0.386 \mathrm{Wm}^{-2}$. This is equivalent to conducting a $0.1 \%$ measurement with respect to the global average ISR.

[1] provide a more stringent absolute accuracy requirement at $<0.1 \mathrm{Wm}^{-2}$ on account of the small absolute magnitude of EEI and its long-term variability of the order of tenths of $\mathrm{Wm}^{-2}$. Studies deriving EEI from ocean heat content changes (plus small contributions from changes in ice, land, and the atmosphere) report uncertainties in the range of \pm 0.1 to \pm 0.4 $\mathrm{Wm}^{-2}$ (e.g., [1][13][16][27]), again suggesting a target accuracy better than the $\pm 0.4 \mathrm{Wm}^{-2}$ derived above. The lack of an established target accuracy emphasizes the need for community-wide research on requirements.

Following equation 4 , we estimate the accelerations due to radiation pressure $\left(\mathrm{a}_{\mathrm{R}}\right)$ acting on a spherical, perfectly absorbing $(\mathrm{K}=1)$ spacecraft with mass of $50 \mathrm{~kg}$ and radius of $0.5 \mathrm{~m}$ for the different radiative flux components outlined above. The estimated accelerations, global mean fluxes and required accuracy are presented in Table 1. The magnitude of accelerations due to the shortwave and longwave fluxes are on the order of 0.5 to $2 \cdot 10^{-8} \mathrm{~ms}^{-2}$. Their uncertainty is between 0.02 to $1 \cdot 10^{-10} \mathrm{~ms}^{-2}$, a similar magnitude as for the global mean value of EEI at about $3 \cdot 10^{-11} \mathrm{~ms}^{-2}$. From this we deduce that an

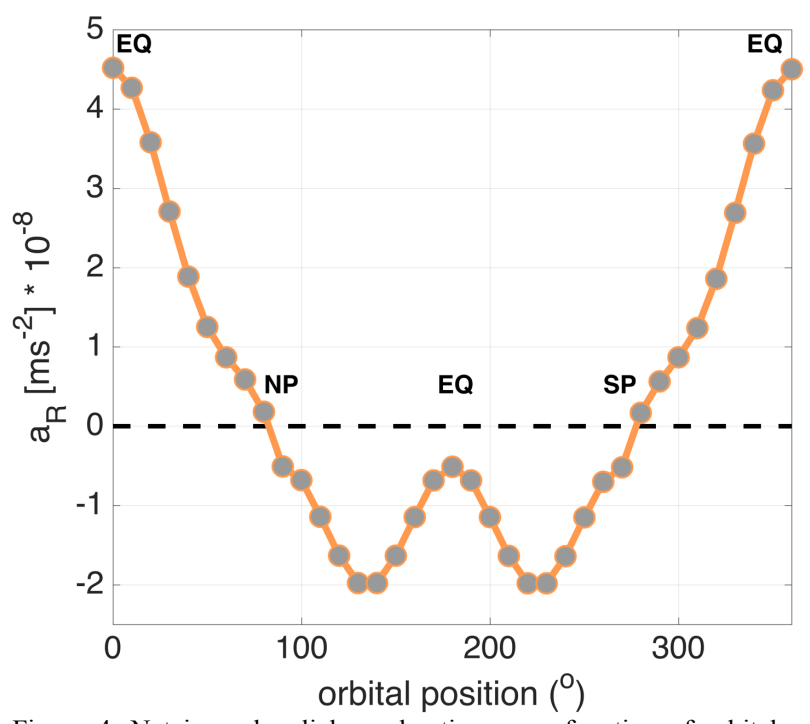

Figure 4. Net inward radial acceleration $a_{R}$ as function of orbital position, assuming a perfectly absorbing spherical spacecraft $(\mathrm{m}=50 \mathrm{~kg}, \mathrm{r}=0.5 \mathrm{~m})$ in a circular orbit $(1300 \mathrm{~km})$ that crosses the equator at solar noon (solar equinox). 
instrument accuracy of the order of $10^{-11}$ or even $10^{-12} \mathrm{~ms}^{-2}$ is necessary to meet the requirements for Earth radiation budget studies. Figure 4 shows the net inward radial acceleration as simulated at different orbital positions in an idealized setup (aqua planet) for a perfectly absorbing spacecraft in a polar orbit crossing the equator at local noon. While the global mean EEI requires an acceleration sensitivity at about $10^{-11} \mathrm{~ms}^{-2}$, the acceleration due to local changes in EEI ranges between -4 to $5 \cdot 10^{-8}$. Therefore, the steps to be taken to aggregate the measurements in time and space to an annual global mean estimate of EEI will be just as essential as the measurement accuracy itself in keeping the uncertainty small.

\section{CONFOUNDING VARIABLES}

A number of confounding variables introduce uncertainty in the relation between EEI and the measured acceleration from radiation pressure (e.g., [46][48]). A list of such potentially perturbing forces and their estimated average magnitude is provided in Table 2 based on the assumption of a spherical spacecraft $(\mathrm{r}=0.5 \mathrm{~m}, \mathrm{~m}=50 \mathrm{~kg})$ in a circular orbit at $1300 \mathrm{~km}$ altitude. CACTUS studies (e.g., [53]) found most of the perturbing forces to be negligibly small with respect to the measurement accuracy achieved by the accelerometer at that time $\left(\sim 10^{-10} \mathrm{~ms}^{-2}\right)$. In light of a new generation of instruments and their higher sensitivity $\left(10^{-11}-10^{-12} \mathrm{~ms}^{-2}\right)$, the role of confounding variables is revisited here.

In the present paper, we focus on the three largest perturbing forces: the residual atmospheric drag, gravity, and the Yarkovsky effect. The magnitude of the average acceleration due to atmospheric drag is at $10^{-9} \mathrm{~ms}^{-2}$ (Table 2) ten times larger than the variations due to radiation pressure $\left(10^{-8} \pm 10^{-11} \mathrm{~ms}^{-2}\right)$. However, for a circular orbit and a spherical satellite, the drag force is directed along the satellite's velocity vector or travel direction [54], respectively, hence acts orthogonal to the radial acceleration component. The associated lift effect at $1300 \mathrm{~km}$ is negligible [55][56] on spherical or near-spherical space crafts [57] and might not affect the direct measurement of EEI via the radial acceleration component either. Nevertheless, [58][59] have noted that slight departures from perfect sphericity induce significant changes in drag effects. The study of capabilities to design the spacecraft as spherical as possible and the effect of departure is therefore crucial. To achieve an EEI measurement within $\pm 0.1 \%$ of ISR, strict requirements must follow for the circularity of the orbit $(<0.3 \%)$, the sphericity of the spacecraft $(<0.1 \%)$, and knowledge of its orientation ( \pm 22 arc min, $<0.1 \%)$.

Gravitational variations are another form of parasitic force acting on the spacecraft with a magnitude of approximately $10^{-}$ ${ }^{5} \mathrm{~ms}^{-2}$. However, these variations act in common mode on both the outer shell of the spacecraft and inner test mass of the accelerometer. Thus, the perturbing effect of gravitational variations on the direct measurement of radiation pressure is negligible.

Another disturbance follows from the acceleration due to thermal push induced by thermal gradients on the satellite skin and the anisotropy of its own thermal radiation. This effect is widely known as Yarkovsky effect and can be determined, knowing the temperature of the body following equation 5 after
[60] and [61] who computed the thermal push of LAGEOS. Here, we assume for a black sphere, due to sun and Earth irradiances, an equilibrium temperature $T_{0}$ at $330 \mathrm{~K}$ and a temperature gradient $\Delta T$ at $300 \mathrm{~K}[62]$.

$$
F_{T H}=\frac{16}{9} \frac{\varepsilon \sigma}{c} \pi r^{2} T_{0}^{3} \Delta T(5)
$$

The associated acceleration is then at about $6 \cdot 10^{-8} \mathrm{~ms}^{-2}$. Potential reduction of thermal gradients and associated emissivity variations could be achieved by spinning the satellite in orbit around its radial axis. For CACTUS, studies [53] estimated thermal thrust at about $10^{-10} \mathrm{~ms}^{-2}$ at a spin frequency of $10^{-3} \mathrm{~Hz}$, resulting in $\Delta T$ at $80 \mathrm{~K}$. The optimal spin frequency for the observing system presented here will depend on the satellite skin characteristics and accuracy requirements.

The other perturbing forces listed in Table 2 have been estimated for CACTUS at magnitudes smaller than $10^{-10} \mathrm{~ms}^{-2}$ (e.g., [53][62]). While this magnitude was considered small with respect to the achieved measurement accuracy at that time, it now becomes potentially disturbing at improved instrument accuracy. Hence, revisiting the role and reducing the impact of these perturbing forces will be essential for the measurement of EEI with present-day capabilities.

CONFOUNDING VARIABLES AT 1300KM

\begin{tabular}{|c|c|c|}
\hline $\mathrm{CF}$ & $\begin{array}{c}\text { MAGNITUDE } \\
\text { OVER ORBIT } \\
\left(\mathrm{MS}^{-2}\right) \\
\end{array}$ & derivation $\&$ treatment \\
\hline atm. drag & $\sim 1.6 \cdot 10^{-9} \pm 3 \cdot 10^{-9}$ & $\begin{array}{l}1 / 2 \rho \mathrm{V}^{2} \mathrm{C}_{\mathrm{d}} \pi r^{2} / \mathrm{m} \\
\text { may not affect EEI measurement via } \\
\text { radial component of acceleration }\end{array}$ \\
\hline gravity & $\sim 9 \cdot 10^{-5}$ & $\begin{array}{l}\text { estimated from GRACE } \\
\text { common mode for shell and inner test } \\
\text { mass of accelerometer }\end{array}$ \\
\hline $\begin{array}{l}\text { Yarkovsky } \\
\text { effect }\end{array}$ & $6 \cdot 10^{-8} \mathrm{~ms}^{-2}$ & $\begin{array}{l}\text { equation } 5 \text { with } \mathrm{T}_{0}=330 \mathrm{~K}, \Delta \mathrm{T}=300 \mathrm{~K} \\
\text { spinning }\end{array}$ \\
\hline $\begin{array}{l}\text { electrical } \\
\text { drag }\end{array}$ & $\begin{array}{l}<10^{-10} \mathrm{~ms}^{-2} \text { or } 1.6 \\
\mathrm{Wm}^{-2}\end{array}$ & Cactus studies \\
\hline $\begin{array}{l}\text { lunar } \\
\text { illumination }\end{array}$ & $<10^{-10} \mathrm{~ms}^{-2}$ & Cactus studies \\
\hline $\begin{array}{l}\text { Lorentz } \\
\text { force }\end{array}$ & $<10^{-10} \mathrm{~ms}^{-2}$ & Cactus studies \\
\hline $\begin{array}{l}\text { Poynting } \\
\text { Robertson }\end{array}$ & $<10^{-10} \mathrm{~ms}^{-2}$ & Cactus studies \\
\hline solar wind & $<10^{-10} \mathrm{~ms}^{-2}$ & Cactus studies \\
\hline $\begin{array}{l}\text { inertial } \\
\text { acceleration }\end{array}$ & $<10^{-10} \mathrm{~ms}^{-2}$ & Cactus studies \\
\hline $\begin{array}{l}\text { magnetic } \\
\text { field force }\end{array}$ & $<10^{-10} \mathrm{~ms}^{-2}$ & Cactus studies \\
\hline
\end{tabular}




\section{PREVIOUS FEASIBILITY STUdiES}

A number of studies [38][53][63] demonstrated the feasibility to estimate TOA radiative fluxes with the ultra-sensitive CACTUS accelerometer that flew onboard CASTOR in $1975 / 76$ as the first of its kind. One-year worth of data was collected with sufficient accuracy to determine seasonal and latitudinal variations in ISR (at day-night transitions), IR (in shadow), and EEI (or net radiative flux) between $30^{\circ} \mathrm{S}$ and $30^{\circ} \mathrm{N}$. The derived IR flux varied considerably between clear and overcast periods, as well as over land and ocean, hence allowed to get a sense of cloud effects and land-sea contrasts typical for IR variations. Overall, the derived radiation fluxes qualitatively agreed well with data from satellite radiometry [64]. Figure 5 depicts the zonal variations in annual mean EEI derived from radial accelerations (acc., CACTUS) and modern radiometric data (CERES EBAF edition 4.0, 2000-2017). The accelerometric estimates exhibit a systematic offset with respect to the CERES data at almost $20 \mathrm{Wm}^{-2}$. The dashed lines represent measures of internal spatial and temporal variability in terms of standard deviation $(\sigma)$ of monthly anomalies. $\sigma \mathrm{s}$ represents the spatial scatter of monthly $1^{\circ} \times 1^{\circ}$ anomalies per latitude zone (equation 7 in [65]), while $\sigma_{\mathrm{T}}$ represents the temporal scatter of zonally averaged monthly anomalies (equation 8 in [65]). The accelerometric estimates are well outside the $\sigma_{\mathrm{T}}$ and $\sigma_{\mathrm{S}}$ lines, meaning the large difference cannot be explained by natural variability. The reason for this discrepancy is not fully known, but was partly attributed to wrongly assigned radiation pressure coefficients needed to translate the measured radial accelerations into radiative flux [53]. Nevertheless, given the high sensitivity to spatial and seasonal variations in radiative flux, an observation system optimally designed for the measurement of EEI, in which biases are known and can be eliminated, will allow to improve absolute accuracy.

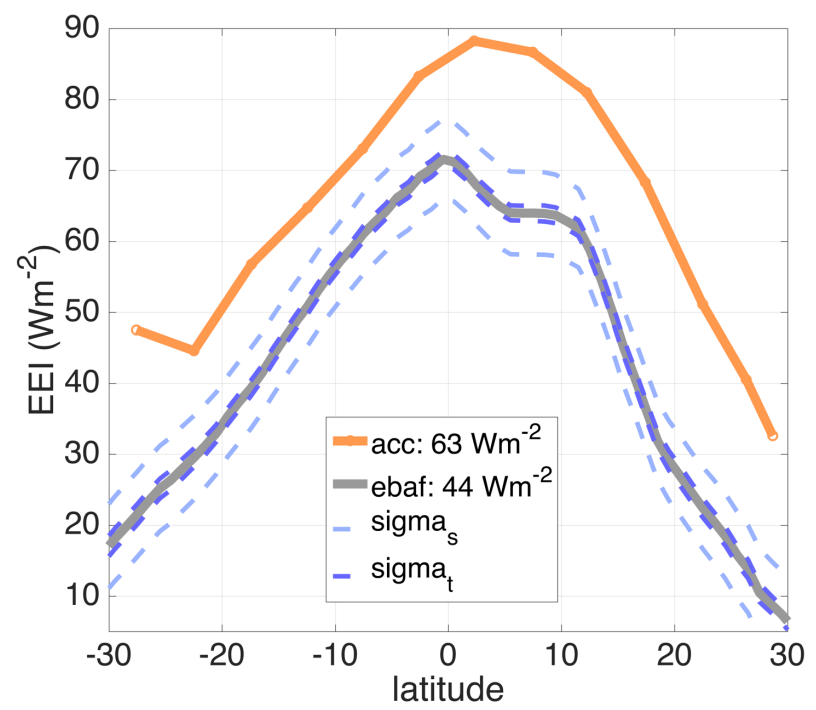

Figure 5: Zonal averages of TOA net radiation flux $\left(\mathrm{Wm}^{-2}\right)$ derived from CACTUS accelerations (1975-1976, orange) and CERES EBAF (2000-2017, gray) between $30^{\circ} \mathrm{S}-30^{\circ} \mathrm{N}$. Bright blue dashed lines represent the spatial $\pm 1 \sigma_{\mathrm{s}}$ of monthly $1^{\circ} \times 1^{\circ}$ anomalies per latitude (equation 7 in Kato, 2009), while the dark blue lines represent the temporal $\pm 1 \sigma_{\mathrm{t}}$ of zonally averaged monthly anomalies (equation 8 in Kato, 2009).
The almost spherical (radius: $0.8 \mathrm{~m}$, mass: $76 \mathrm{~kg}$ ) CASTOR was originally developed to measure air-density and detect micrometeoroids in low atmospheric density (apogee: 1270km, perigee: $270 \mathrm{~km}$, inclination: $30^{\circ}$ ). The achieved measurement sensitivity exceeded expectations and was further augmented using statistical methods [38] reaching $10^{-10} \mathrm{~ms}^{-2}$ (or about 1 $\mathrm{Wm}^{-2}$ ), which ultimately allowed the first evaluation of EEI from space. Overall, the CACTUS studies concluded that accelerometry provides viable means to observe the EEI, but recommended to consider a different choice for satellite skin material, orbit definition, and good knowledge of attitude parameters. ESA's BIRAMIS project studies [48] did consider a more suitable concept design that improved the accuracy of the measurement as it relates to EEI. The uncertainty was at about $3 \mathrm{Wm}^{-2}$ (only accelerometer measurement error) still an order of magnitude above present-day requirements $\left(\sim 0.3 \mathrm{Wm}^{-}\right.$ 2).

Data from high precision accelerometers flown on missions such as GRACE [66], or GOCE [67] are potentially useful to study the impact of radiation pressure on Earth orbiting satellites over the past decade, although these missions are not optimized for such measurement. The satellites' non-uniform shape, inadequate characterization of thermo-optical properties and thermal control, as well as their relatively low orbits confound the measurement. While these data will not provide an estimate of EEI at high accuracy, they might allow to reproduce the amplitude of radiation variability to some degree, and provide insights into the change of satellite skin properties over time (see also Section VIII).

\section{INSTRUMENT DESIGN: MICROSTAR}

Since the employment of CACTUS in 1975, the French Aerospace Lab ONERA has built new accelerometers based on the same principle, but with improved performance that were launched in missions like CHAMP (2000) [68], GRACE (2002) [66], GOCE (2007) [67] and GRACE-FO (scheduled in 2018) [69]. For the measurement of EEI, a sensitivity of at least $10^{-11}$ $\mathrm{ms}^{-2}$ is required, at least for the accelerations along the radial axis. To further provide good attitude control of the satellite, an accelerometer providing angular acceleration is a great advantage. Here, we propose to use the accelerometer MicroSTAR, that was built based on similar principles as the previous generation, with a cubic proof-mass, but with three very sensitive axes instead of only two, providing angular accelerations at high accuracy [70]. The instrument's measurement accuracy is required to be $<0.1 \%$, which implies a specification of the scale factor of the instrument.

\section{A. Description}

The principle of electrostatic accelerometers is to control a free proof-mass to be motionless inside an electrode cage. The force applied to maintain the proof-mass at the center of the electrode cage is proportional to the relative acceleration between the proof-mass and the electrode cage, which is fixed in the satellite. If the accelerometer is at the center of mass of the satellite, the proof-mass experiences the same gravity acceleration as the satellite, but the satellite is exposed to the 


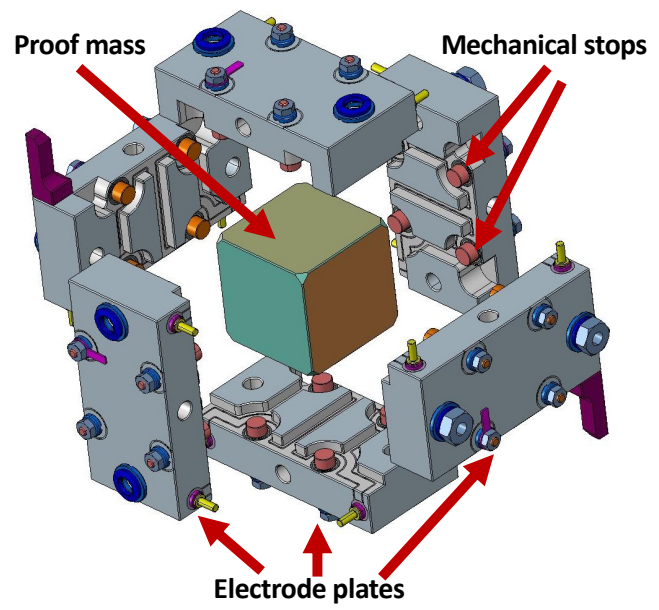

Figure 6. Mechanical core of the MicroSTAR accelerometer.

surfaces forces, such as atmospheric drag and radiation pressure. Consequently, the accelerometer measures only the non-gravitational accelerations.

In case of ONERA's electrostatic accelerometers, the proofmass motion is precisely measured through capacitive detection between proof-mass and the electrodes [71]. A controller applies voltages to the same electrodes in order to create electrostatic forces, which counteract the relative acceleration between proof-mass and the electrode cages due to nongravitational forces. The measurement of the accelerometer is therefore the voltages applied to the electrodes [72].

The electrode cage of MicroSTAR is composed of six Ultra Low Expansion material (ULE) electrode plates with two electrodes that surround a cubic $30 \times 30 \times 30 \mathrm{~mm}$ proof-mass (Figure 6). The electrode plates are manufactured with patented 3-Dimensional Ultra Sonic machining to draw the electrodes. The electrode surfaces are covered with a conductive metallic coating manufactured using a Physical Vapor Deposition (PVD) process. The mechanical core of the accelerometer is fixed on a sole plate and enclosed in a hermetic housing in order to maintain cleanliness and vacuum around the proof-mass. The proof-mass is polarized with a very thin wire.

The two pairs of electrodes of each axis control two degrees of freedom, one translation and one rotation of the proof-mass. The accelerometer electronic architecture is composed of six control loops, one for each degree of freedom of the proof-mass. Along each of the three axes, one translation and one rotation are controlled by similar schemes. The electronic boards with the capacitive detector, controller and drive voltage amplifier take advantage of the previous accelerometers design with low noise and low consumption analog functions.

The total weight of the accelerometer is estimated at $9.5 \mathrm{~kg}$, with a power consumption of $10 \mathrm{~W}$.

\section{B. Performance}

In reality, due to the non-perfect location of the accelerometer at the center of mass of the satellite, the acceleration at accelerometer location $\underline{a}_{A c c}$ is perturbed by the gravity gradient
([U]), the attitude control $([\Omega] \text { and }[\dot{\Omega}])^{1}$, and by the motion of the accelerometer location $\underline{r}_{A c c}$ with respect to the center of mass $\underline{r}_{C o M}$, according to (6):

$$
\begin{gathered}
\underline{a}_{A c c}=\underline{a}_{N G}+\left(-[U]+[\dot{\Omega}]+\left[\Omega^{2}\right]\right)\left(\underline{r}_{A c c}-\underline{r}_{C O M}\right)+ \\
2[\Omega]\left(\dot{r}_{A c c}-\underline{\dot{r}}_{C O M}\right)+\left(\underline{\dot{r}}_{A c c}-\ddot{\dot{r}}_{C O M}\right)
\end{gathered}
$$

To minimize the perturbation, it is important to localize the accelerometer at the center of mass of the satellite. Moreover, it is important to avoid any motion inside the satellite, such as liquid propellant.

Furthermore, the measurement suffers of scale factor error [K], alignment error [R], coupling error [S], quadratic factor [K2], bias $\underline{\mathrm{b}}$ and noise $\underline{\mathrm{n}}$ :

$$
\underline{a}_{\text {Meas }}=([I]+[K]+[S]+[R]) \underline{a}_{A c c}+[K 2] \underline{a}_{A c c}^{2}+\underline{b}+\underline{n}
$$

For this mission, the proof-mass is made of Arcap alloy, with a weight of $218 \mathrm{~g}$. The gap between electrodes and the proofmass is chosen at $400 \mu \mathrm{m}$ in order to achieve the requirement. The accelerometer range is at $3.5 \cdot 10^{-6} \mathrm{~ms}^{-2}$ larger than the maximum acceleration level given in Table 2 (we recall that the gravity acceleration is not seen in the measurement).

The measurement suffers from an important bias due to the stiffness of the thin wire which polarizes the proof-mass (and avoids charging in orbit). The level is evaluated to less than $1.8 \cdot 10^{-6} \mathrm{~ms}^{-2}$ and shall be calibrated or rejected in orbit (see section VII C).

Figure 7 provides the spectral density of the noise and its main contributors according to the mathematical model of the accelerometer noise confirmed by previous missions [73].

Considering a spin frequency at $10^{-3} \mathrm{~Hz}$, the accuracy of the measurement corresponds to the noise at this frequency $\left(10^{-11}\right.$ $\mathrm{ms}^{-2} / \mathrm{Hz}^{1 / 2}$ ) multiplied by the square root of the frequency, which gives an accuracy of $3 \cdot 10^{-13} \mathrm{~ms}^{-2} \mathrm{rms}$. This translates into $0.01 \mathrm{Wm}^{-2}$ using equation 4 .

The other contributors of error will be minimized to have a negligible impact. For example, to avoid the projection of atmospheric drag along the track of the radial measurement, the alignment and coupling of the accelerometer shall be better than $100 \mu \mathrm{rad}$, which was realized in the GOCE mission.

\section{Calibration}

The electrostatic accelerometer suffers of an important bias, which shall be calibrated in order to be suppressed and to have long-term stability of the measurement. If the accelerometer is regularly turned by $180^{\circ}$ with respect to the external acceleration, the signal in the measurement will change sign, but not the bias, allowing to correct for it. One can also consider a continuous spin of the instrument in order to modulate the external acceleration at spin frequency.

To do that, we propose to profit from the satellite spin used to equalize the satellite temperature and the thermo-optical properties along the irradiance direction. It is also possible to add a bias rejection system, which consists in general of a

\footnotetext{
${ }^{1}$ Underlined letters refer to a vector, while a letter between square brackets refers to a matrix.
} 


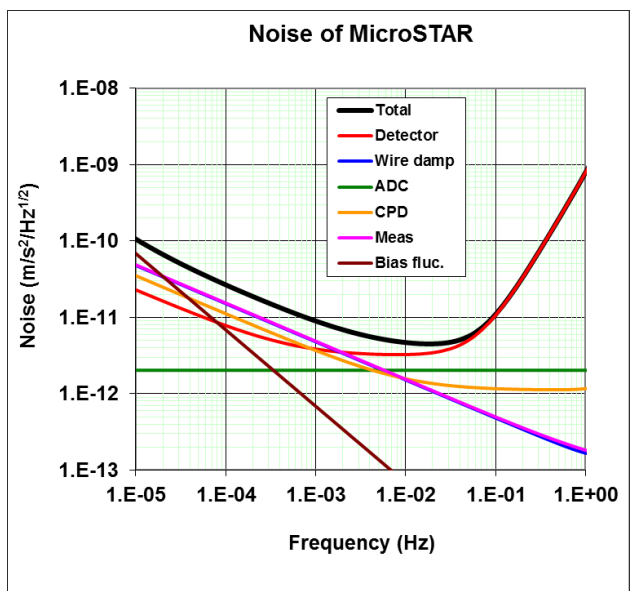

Figure 7. Noise Performance of the MicroSTAR accelerometer with the main contributors: detector noise (red), thin wire damping (blue), measurement analog digital converter (green), contact potential difference (yellow), measurement analog noise (magenta), and bias fluctuation noise (brown).

rotating platform inside the satellite [74] [75]. A combination of these methods can be used to calibrate along all three axes: Calibration along the radial axis could be achieved by spinning add a bias rejection system, which consists in general of a rotating platform inside the satellite [74] [75]. A combination of these methods can be used to calibrate along all three axes: Calibration along the radial axis could be achieved by spinning around the along- or cross-track axis, but this would hamper the communication to Earth or GPS. Adding a bias rejection system (rotating platform) to reject the bias along the radial axis together with a spin around the radial axis (at different frequencies) provides the means to reject the bias along all three directions.

The accelerometer scale factor will be estimated on ground from the accurate measurement of its contributing sources, in particular the electrode surface and gap. These two main contributions do not vary in orbit, except through the temperature effect, which shall be accurately measured on board. An in-flight calibration of the scale factor is possible in orbit through the comparison of GPS position, knowledge of Earth's gravity field, and the accelerometer measurement along one orbit, but the accuracy of such calibration is to be assessed.

\section{SPACECRAFT DESIGN AND PAYLOAD}

Important requirements of the prospective satellite system besides size, mass, and power consumption, concern the spacecraft's shape and coating characteristics. The satellite is not only the carrier of instrumentation but part of the measurement system itself, transforming the impinging irradiances into measurable accelerations.

The employment of near-spherical spacecrafts is state-of-theart in improving atmospheric density models essential for precision orbit determination [54][76]. The LAGEOS missions and their observed orbital decay [77] identified particle drag and radiation dependent forces as significant perturbations to a satellite's position in orbit. Likewise, a more recent mission, the Drag and Atmospheric Neutral Density Explorer (DANDE, [78][79]), aims at improving the understanding of the satellite drag environment in the lower thermosphere, but lost contact to ground systems shortly after launch.

Since attitude motions neither change the cross-sectional area nor the area-to-mass ratio of a spherical spacecraft, the measurement of non-gravitational forces is simplified, which helps to reduce uncertainties in the quantification of drag coefficients [59] and radiation pressure [53].

As outlined in section III, the spherical shape of the spacecraft is a crucial requirement for the successful monitoring of EEI via the measurement of radial accelerations and will reduce the perturbing impact of atmospheric drag. The design of a perfectly spherical spacecraft is likely impossible. An assessment of different near-spherical shapes that yield the required measurement accuracy is needed to provide design requirements.

To study satellite shape and skin material implications for BIRAMIS, ONERA and Aeritalia conducted payload and satellite definition studies with assistance by ESA [48]. To find a material with constant coating property coefficient $\mathrm{K}$ close to 1, ONERA measured different skin material's optical properties at various wavelengths and angles of incidence. The two most stable choices were mechanically polished aluminum coated with MgF2 (specular reflecting) or black painted honeycomb (absorbing), as they induced the smallest measurement errors according to their numerical model [48]. The studies found that variations in spectral absorption coefficient by $10 \%$ yield $1 \%$ variations in $\mathrm{K}$, concluding that variations of optical properties with wavelength or ageing did not significantly modify $\mathrm{K}$ and therefore the measurement itself. Targeting EEI measurements to within at least $\pm 0.3 \mathrm{Wm}^{-2}$, knowledge of $\mathrm{K}$ has to be better than $\pm 0.1 \%$; acceptable variability in $K$ and the effect of degradation due to long duration exposure require reassessment with respect to the target accuracies proposed here.

Liquid fuel disturbs the accelerometric measurement, hence solar cells and batteries are required to provide the needed power (estimated at $90 \mathrm{~W}$ for BIRAMIS) during sunlight and eclipse. Ultimately, the number of solar cells needed depends on size, mass, surface area and power consumption of the spacecraft. A relatively large surface area of about 30\% was estimated to be covered by solar cells in case of BIRAMIS $(\mathrm{r}=1 \mathrm{~meter}$, mass $=225 \mathrm{~kg})$, distributed in a uniform patchwork pattern.

The accelerometer and a rotating platform for inflight calibration represent the primary payload of the spacecraft. Solar sensor and star trackers essential for attitude determination, as well as a GPS receiver and patch antenna for data transmission, ideally will not hamper significantly with the spherical shape and thermo-optical properties of the spacecraft. Given the different surfaces and non-uniform exposure to solar UV radiation that causes degradation, it is clear that the spacecraft will neither be perfectly absorbing nor spatially uniform. The radial spin and near-spherical shape of the satellite will help equalize varying non-isotropic thermo-optical properties, but the sun facing side may undergo more substantial degradation due to UV exposure and induce gradients in surface absorptivity. $\mathrm{K}$, its change in time as function of wavelength, as well as the errors induced, will have to be estimated for all materials. Future assessment of coating types should also consider the minimization of thermal 
gradients that induce thermal thrust and thermo-structural deformations that lead to perturbing inertial accelerations.

Besides shape and satellite skin, we may think about maximizing the cross-section over mass ratio, which would enhance the acceleration measurement according to equation (2). Balloon-shaped satellites, such as the passive communication experiments Echo [80] or PAGEOS represent a possible scenario. However, the viability of such a construction carrying an active instrument is questionable, since the risk of thermo-structural deformations, as occurred with ECHO I, has to be considered.

\section{ORBIT \& SAMPLING}

The orbit choice is dictated by the need to minimize perturbing forces, such as atmospheric drag, the effects of energetic particles (Van Allen belts), and the need for global sampling. A compromise between those needs requires a near-circular orbit higher than $1000 \mathrm{~km}([81][48][46])$ with an inclination of $90^{\circ}$. To satisfy first-order spatio-temporal coverage requirements of measuring the radiation fluxes at six different longitudes and six latitudes at four times a day, the best configuration is met with three orbital planes, one of which is polar $\left(90^{\circ}\right)$ and the others slightly inclined. Each orbit is to be equipped with a spacecraft at $1300 \mathrm{~km}$, an orbit altitude that represents a "sweet spot" of view factor (0.08) and period (112 minutes).

These findings are in line with [81], who describe two and three satellite combinations to be most adequate in providing monthly global mean albedo and thermal radiation estimates based on WFOV sensors (non-scanning) within $1 \%\left(\sim 2 \mathrm{Wm}^{-2}\right)$ to a simulated global mean reference. This sampling error is still large and attributable to the difficulty of measuring and modeling the diurnal cycle sufficiently [82]. Even in case of the scanning CERES radiometers, where models can be used to augment the temporal sampling, a substantial error due to incomplete diurnal sampling has been identified: By adding more complete diurnal cycle information from geostationary satellites, the EEI derived from CERES is reduced by about 1 $\mathrm{Wm}^{-2}$ [42]. The impact of incomplete diurnal sampling of RSR and IR on regional trends and interannual variability is, however, insignificant [83].

Meeting the accuracy goal of $\pm 0.3 \mathrm{Wm}^{-2}$ or better, will require in-depth analysis and simulation of radiation pressure acceleration for different numbers of satellites and orbits using hourly radiation data. Such data can be obtained from CERES (https://ceres.larc.nasa.gov/products.php?product=SYN1deg) or from global climate model simulation. This future study will show whether more satellites are needed to resolve the mean diurnal cycle of EEI adequately and if interpolation techniques can help reduce sampling errors. A study by [84] found that a constellation of 36 satellites is needed to estimate global daily mean shortwave and longwave outgoing radiation to within $0.16 \mathrm{Wm}^{-2}$ and $-0.13 \mathrm{Wm}^{-2}$. Given that we aim at longer-term estimates of annual or potentially monthly resolution, a less dense coverage is likely sufficient. In addition to global annual and monthly mean EEI estimates, a data product of zonal resolution would meet GCOS requirements as aimed at by CLARREO [85], a radiometric mission that aims at providing TOA radiation balance components at high spectral resolution.
While we aim at high accuracy for global annual mean EEI to facilitate climate change detection studies, lower accuracy is sufficient to monitor seasonal and spatial variability (see section II).

\section{Challenges \& OUTLOOK}

In this paper, we have outlined the complexity of estimating Earth's energy imbalance (EEI) directly from space. The measurement of the integrated value of EEI, as opposed to its radiative components, is a major challenge faced by the climate science community and requires rethinking our capabilities. While it is probable that radiometry may never provide the accuracy needed to pinpoint the true magnitude of EEI, the measurement of the individual radiative components is indispensable in understanding the causes of perturbations to the energy budget, addressing the question why the input of heat changes. Temporal ocean heat content changes represent to date the sole source of meaningful EEI estimates over the last decade, albeit sampling errors and the integration of additional sinks and sources of heat, such as ice melt that continuous to rise in a warming world [86], represent challenges. Vital information on the horizontal and vertical distribution of heat uptake are unique to the Argo observing system, irreplaceable by remote sensing techniques, and address the question on where the heat goes. Here, we propose to complement these existing observation systems by adding a third observation pillar that explicitly monitors how much heat is accumulated by our planet in the global mean, providing closure of the energy balance from space. A target accuracy for measurements of global mean EEI is not established by the community, but falls within \pm 0.1 to $\pm 0.3 \mathrm{Wm}^{-2}$ according to Argo-based capabilities [1] and GCOS recommendations for energy budget studies [52]. Additional information on the zonal distribution of EEI would provide some information on where the heat goes and serve for regional energy budget studies and inter-comparisons between products.

Here, we revisited the methodology of deriving the net radiation flux at TOA from the net radiation pressure force acting on Earth orbiting spacecrafts. The feasibility has been demonstrated in the past by missions like CASTOR, which carried the CACTUS accelerometer [38], and proposed concept studies leading to an unfulfilled mission, BIRAMIS [48]. Since then, the measurement accuracy of the ultra-sensitive accelerometers employed to measure non-gravitational forces has greatly improved and a measurement of net radiative flux to within $\pm 0.3 \mathrm{Wm}^{-2}$ or better is within reach, depending on spacecraft design and orbital considerations that shape the measurement sensitivity and accuracy in their own way. The spacecraft itself represents an integral part of the measurement system as it converts the impinging irradiances into measurable accelerations. Requirements concerning the spacecraft's shape and optimal skin coating characteristics will continue to be subject of research.

Perturbing forces, such as atmospheric drag and the Yarkovsky effect, need to be thoroughly identified, their impact quantified, and eventual solutions presented. The two above mentioned effects become negligible when we consider a spinning, spherical spacecraft at an orbit altitude greater than $1000 \mathrm{~km}$. 
TABLE 3

OUTSTANDING NEXT STEPS

\section{REFERENCES}

1. Define target accuracy, which is not established by community, but appears to converge to within \pm 0.1 to $\pm 0.3 \mathrm{Wm}^{-2}$ for longterm global mean EEI.

2. Simulation of radial accelerations as experienced by spacecraft due to Sun and Earth radiation, i.e. the net radiative flux or EEI, to assess accuracy of local measurement for different time and space resolutions, illumination angle, weather conditions, and space craft characteristics.

3. Study of diurnal cycle representation and associated sampling error for one, two, or three satellite systems. Identify optimum configuration for global mean sampling in annual and monthly mean and establish interpolation techniques to mitigate error.

4. Assessment of confounding variables and their error contribution with respect to established target accuracy. Establish solutions to reduce impact of perturbing forces.

5. Spacecraft and mission design studies with focus on shape, thermo-optical properties, thermal control, degradation, and associated impacts on absorptivity and emissivity.

These requirements and related uncertainties need to be modeled and quantified within the trade space of estimating the EEI most accurately to within at least $\pm 0.3 \mathrm{Wm}^{-2}$. This trade space may yield different solutions that depend on the ultimate goal of either aiming at the most accurate local estimate or the best-possible global mean. Considering the latter, spatial and temporal averaging will likely smooth out the noise and uncertainty induced by perturbing effects and design flaws of an imperfect observing system.

Similarly, the methodology of spatial and temporal sampling, by employing one or multiple spacecrafts and their added value, requires further evaluation. Finally, the processing of the measured accelerations will require thorough conversion, deconvolution to an optimal TOA level, and averaging algorithms that will provide global and zonal mean EEI at annual and potentially monthly time scales that meet the requirements of the community. Table 3 summarizes the outstanding issues to address in order to establish a complete error budget of error sources, their contribution to measurement uncertainty, and solutions for their mitigation. The present paper has highlighted and in part quantified these issues and potential solutions. Showstoppers are so far not identified, paving the way to a better understanding of global climate change through an independent measurement of Earth's energy imbalance from space.

\section{Acknowledgment}

The research was carried out at the Jet Propulsion Laboratory (JPL), California Institute of Technology, under a contract with the National Aeronautics and Space Administration. We would like to acknowledge the participants of the A-team study conducted at JPL who helped develop this research. This work was supported under NASA contract NNN12AA01C.

Copyright 2018. All rights reserved.
[1] K. Von Schuckmann, M. D. Palmer, K. E. Trenberth, A. Cazenave, D. Chambers, N. Champollion, J. Hansen, S. A. Josey, N. Loeb, P. -P. Mathieu, B. Meyssignac, and M. Wild, "An imperative to monitor Earth's energy imbalance," Nature Clim. Change, vol. 6, no. 2, pp. 138-144, 2016. DOI: 10.1038/nclimate2876.

[2] K. E. Trenberth, J. T. Fasullo, K. Von Schuckmann, and L. Cheng, "Insights into Earth's Energy Imbalance from Multiple Sources," Journal of Climate, vol. 29, no. 20, pp. 7495-7505, 2016. DOI: 10.1175/JCLI-D-16-0339.1.

[3] L. Cheng, K. E. Trenberth, J. T. Fasullo, T. Boyer, K. Von Schuckmann, and J. Zhu, "Taking the pulse of the planet," Eos, vol. 98, Sep. 2017. DOI: 10.1029/2017EO081839.

[4] J. Gould et al., " Argo profiling floats bring new era of in situ ocean observations", Eos, vol. 8, no. 19, pp. 185-191, 2004. DOI: $10.1029 / 2004 E O 190002$.

[5] S. Riser et al. (28 co-authors), "Fifteen years of ocean observations with the global Argo array," Nature Climate Change, vol. 6, pp. 145-153, 2016. DOI: 1038/NCLIMATE2872.

[6] M.A. Balmaseda et al., " The Ocean Reanalyses Intercomparison Project (ORA-IP)," Journal of Operational Oceanography, vol. 8, pp. 80--97, 2015. DOI: 10.1080/1755876X.2015.1022329.

[7] M.D. Palmer, C.D. Roberts, M. Balmaseda, Y.S. Chang, G. Chepurin, N. Ferry, Y. Fujii, S. A. Good, S. Guinehut, K. Haines, F. Hernandez, A. Köhl, T. Lee, M. J. Martin, S. Masina, S. Masuda, K. A. Peterson, A. Storto, T. Toyoda, M. Valdivieso, G. Vernieres, O. Wang, Y. Xue, "Ocean heat content variability and change in an ensemble of ocean reanalyses," Climate Dynamics, 2015. doi:10.1007/s00382015-2801-0.

[8] W. Llovel, J. K. Willis, F. W. Landerer, and I. Fukumori, " Deep-ocean contribution to sea level and energy budget not detectable over the past decade," Nature Clim. Change, vol. 4, no. 11, pp. 1031--1035, 2014. DOI: 10.1038 nclimate2387.

[9] D.P. Chambers, "Observing seasonal steric sea level variations with GRACE and satellite altimetry," J. Geophys. Res., vol. 111, no. C03010, 2006. DOI:10.1029/2005JC002914.

[10] Rhein, M., S.R. Rintoul, S. Aoki, E. Campos, D. Chambers, R.A. Feely, S. Gulev, G.C. Johnson, S.A. Josey, A. Kostianoy, C. Mauritzen, D. Roemmich, L.D. Talley and F. Wang, 2013: Observations: Ocean. In: Climate Change 2013: The Physical Science Basis. Contribution of Working Group I to the Fifth Assessment Report of the Intergovernmental Panel on Climate Change [Stocker, T.F., D. Qin, G.-K. Plattner, M. Tignor, S.K. Allen, J. Boschung, A. Nauels, Y. Xia, V. Bex and P.M. Midgley (eds.)]. Cambridge University Press, Cambridge, United Kingdom and New York, NY, USA.

[11] J.P. Abraham et al., "A review of global ocean temperature observations: Implications for ocean heat content estimates and climate change," Rev. Geophys., vol. 51, pp. 450-483, 2013. DOI: $10.1002 /$ rog. 20022.

[12] L. Cheng, K. E. Trenberth, J. Fasullo, T. Boyer, J. Abraham, J. Zhu, "Improved estimates of ocean heat content from 1960 to 2015," Science Advances, vol 3, no. 3, 2017. DOI:10.1126/sciadv.1601545.

[13] J.M. Lyman JM, S.A. Good, V.V. Gouretski, M. Ishii, G.C. Johnson, M.D. Palmer, D.M. Smith, J.K. Willis, "Robust warming of the global upper ocean," Nature, vol. 465, pp. 334--337, 2010. DOI: 10.1038/nature09043.

[14] D. Roemmich, J. Church, J. Gilson, D. Monselesan, P. Sutton, Philip, and S.Wijffels, "Unabated planetary warming and its ocean structure since 2006," Nature Clim. Change, vol. 5, no. 5, pp. 240--245, 2015. DOI: 10.1038 /nclimate 2513 .

[15] J. Hansen, L. Nazarenko, R. Ruedy, M. Sato, J. Willis, A. Del Genio, D. Koch, A. Lacis, K. Lo, S. Menon, T. Novakov, 
J. Perlwitz, G. Russell, G.A. Schmidt, and N. Tausnev, " Earth's energy imbalance: Confirmation and implications.," Science, vol. 308, pp. 1431-1435, 2015. DOI: $10.1126 /$ science. 1110252 .

[16] K. von Schuckmann, P.-Y. Le Traon, "How well can we derive Global Ocean Indicators from Argo data?," Ocean Science, vol. 7, no. 6, pp. 783--791, 2011. DOI: 10.5194/os7-783-2011.

[17] D. Desbruyères, E.L. McDonagh, and B.A. King, "Observational Advances in Estimates of Oceanic Heating," Curr Clim Change Rep, vol. 2, no. 127, 2016. DOI: 10.1007/s40641-016-0037-7.

[18] G. L. Stephens, M.Z. Hakuba, M. Hawcroft, et al., "The Curious Nature of the Hemispheric Symmetry of the Earth's Water and Energy Balances," Curr Clim Change Rep, vol. 2, no. 135, 2016. DOI: 10.1007/s40641-016-0043-9.

[19] J.K. Willis, D. Roemmich, and B. Cornuelle, "Interannual variability in upper ocean heat content, temperature, and thermosteric expansion on global scales," J. Geophys. Res., vol. 109, no. C12036, 2004. DOI:10.1029/2003JC002260.

[20] N. G. Loeb, J.M. Lyman, G. C. Johnson, R.P. Allan, D.R. Doelling, T. Wong, B.J. Soden, G.L. Stephens, "Observed changes in top-of-the-atmosphere radiation and upper-ocean heating consistent within uncertainty," Nature Geosci., vol. 5, no. 2, pp. 110--113, 2012. DOI: 10.1038/ngeo1375.

[21] G.L. Stephens, J. Li, M. Wild, C.A. Clayson, N. Loeb, S. Kato, T. L'Ecuyer, P.W Stackhouse, M. Lebsock, and T. Andrews, " An update on Earth's energy balance in light of the latest global observations," Nature Geosci., vol. 5, no. 10, pp. 691--696, 2012. DOI: 10.1038/ngeo1580.

[22] M.D. Palmer, " Reconciling Estimates of Ocean Heating and Earth's Radiation Budget," Current Climate Change Reports, vol.3, no.1, pp. 78--86, 2017. DOI: 10.1007/s40641016-0053-7.

[23] N. G. Loeb, B.A. Wielicki, D.R. Doelling, G.L. Smith, D.F, Keyes, S. Kato, N. Manalo-Smith, and T. Wong, Takmeng," Toward Optimal Closure of the Earth's Top-of-Atmosphere Radiation Budget," Journal of Climate, vol. 22, no.3, pp. 748--766, 2009. DOI: 10.1175/2008JCLI2637.1.

[24] N.G. Loeb, D.R. Doelling, H. Wang, W. Su, C. Nguyen, J.G. Corbett, L. Liang, C. Mitrescu, F.G. Rose, and S. Kato, " Clouds and the Earth's Radiant Energy System (CERES) Energy Balanced and Filled (EBAF) Top-of-Atmosphere (TOA) Edition 4.0 Data Product," Journal of Climate, 2017, DOI: 10.1175/JCLI-D-17-0208.1.

[25] G. C. Johnson, J. M. Lyman, and N. Loeb, "Improving estimates of Earth's energy imbalance," Nature Climate Change, vol. 6, p. 639, 2016. DOI: 10.1038/nclimate3043.

[26] K.E. Trenberth, J.T. Fasullo, "Tracking Earth's Energy," Science, vol. 328, no. 5976, pp. 316, 2010. DOI: $10.1126 /$ science. 1187272 .

[27] K.E. Trenberth, J.T. Fasullo, and M. A. Balmaseda, "Earth's Energy Imbalance," Journal of Climate, vol. 27, no. 9, pp. 3129--3144, 2014. DOI: 10.1175/JCLI-D-13-00294.1.

[28] W. Feng, and M. Zhong, "Global sea level variations from altimetry, GRACE and Argo data over 2005-2014," Geodesy and Geodynamics, vol. 6, no. 4, pp. 274--279, 2015. DOI: 10.1016/j.geog.2015.07.001.

[29] B.D. Tapley, S. Bettadpur, J.C. Ries, P.F. Thompson, M.M. Watkins, "GRACE measurements of mass variability in the Earth system," Science, vol. 304, no. 5683, pp. 503--505, 2004. DOI: $10.1126 /$ science.1099192.

[30] E.W. Leuliette, and R. Scharroo, "Integrating Jason-2 into a Multiple-Altimeter Climate Data Record," Marine Geodesy, vol. 33, pp. 504-517, 2010. DOI: 10.1080/01490419.2010.487795.

[31] S.R. Jayne, J. M. Wahr, and F. O. Bryan, "Observing ocean heat content using satellite gravity and altimetry," $J$. Geophys. Res., vol. 108, no. 3031, 2010. DOI:10.1029/2002JC001619.

[32] R. Rietbroek, S.-E. Brunnabend, J. Kusche, J. Schröter, and C. Dahle, "Revisiting the contemporary sea-level budget on global and regional scales," PNAS, vol. 113, no. 6, pp. 1504 $-1509,2016$. DOI: 10.1073/pnas.1519132113.
[33] L-L. Fu, "On the Decadal Trend of Global Mean Sea Level and Its Implication on Ocean Heat Content Change," Front. Mar. Sci., vol. 3, 2016. DOI: 10.3389/fmars.2016.00037.

[34] H.B. Dieng, A. Cazenave, B. Meyssignac, and M. Ablain, "New estimate of the current rate of sea level rise from a sea level budget approach," Geophys. Res. Lett., vol. 44,pp. 3744-3751, 2017. DOI:10.1002/2017GL073308.

[35] Mauritsen, et al. (2012), "Tuning the climate of a global model," J. Adv. Model. Earth Syst., 4, M00A01, 2012. doi:10.1029/2012MS000154.

[36] F. Hourdin, T. Mauritsen, A. Gettelman, J. Golaz, V. Balaji, Q. Duan, D. Folini, D. Ji, D. Klocke, Y. Qian, F. Rauser, C. Rio, L. Tomassini, M. Watanabe, and D. Williamson, " The Art and Science of Climate Model Tuning," Bull. Amer. Meteor. Soc., vol. 98, pp. 589-602, 2017. https://doi.org/10.1175/BAMS-D-15-00135.1

[37] M.R. Drinkwater, R. Floberghagen, R. Haagmans, D. Muzi, A. Popescu, "GOCE: ESA's First Earth Explorer Core Mission," in: Earth Gravity Field from Space - From Sensors to Earth Sciences, G. Beutler, M.R. Drinkwater, R. Rummel, R. Von Steiger, Ed., Space Sciences Series of ISSI, vol 17. Springer, Dordrecht, 2003. DOI: 10.1007/978-94017-1333-7 36 .

[38] Y. Boudon, "Measurement of the radiation pressure by accelerometry: A new way to the determination of the Earth radiation budget. Result obtained with CASTOR/CACTUS experiment," in: Current issues in Climate Research: Proceedings of the EC Climatology Programme Symposium, A. Ghazi, R. Fantechi, Ed., Springer Netherlands, Dordrecht, pp. 341--352, 1986. DOI: 10.1007/978-94-009-5494-6\32.

[39] A.M. Mainguy, A. Bernard, T. Duhamel, et al., "Biramis -Evaluation numérique de la précision globate du système," in: Rapport technique no7/3373/SY. Contrat ESA. no. 3454/77, march 1980.

[40] A.M. Mainguy, "Projet BIRAMIS- Mesure du bilan radiatif de l'atmosphère terrestre par satellite accélérométrique, " ONERA -- Note technique, July 1981

[41] S.S. Leroy, J.G. Anderson, and G. Ohring, "Climate Signal Detection Times and Constraints on Climate Benchmark Accuracy Requirements," Journal of Climate, vol. 21, 2008. DOI: 10.1175/2007JCLI1946.1.

[42] D.R. Doelling, N Loeb, D. F. Keyes, M. L. Nordeen, D. Morstad, B. A. Wielicki, D. F. Young, and M. Sun, "Geostationary enhanced temporal interpolation for CERES flux products," J. Atmos. Oceanic Technol., vol 30, pp. 1072-1090, 2013.

[43] S.P. Wyatt, "The effect of terrestrial radiation pressure on satellite orbits," in: Dynamics of Satellites / Dynamique des Satellites, M. Roy, Ed., IUTAM Symposia (International Union of Theoretical and Applied Mechanics). Springer, Berlin, Heidelberg, 1963.

[44] L. Sehnal, "Radiation Pressure Effects in the Motion of Artificial Satellites," in: Dynamics of Satellites, B. Morando, Ed., COSPAR-IAU-IAG/IUGG-IUTAM, Springer, Berlin, Heidelberg, 1970.

[45] A.V. Krivov, and J. Getino, "Orbital evolution of highaltitude balloon satellites", Astron. Astrophys., vol. 318, pp. 308--314, 1997.

[46] T.H. Vonder Haar, and E.A. Smith, "Theoretical Comparison Between Radiometric and Radiation Pressure Measurements for Determination of the Earth's Radiation Budget," Atmospheric Science Paper No. 317, July 1979, Department of Atmospheric Science, Colorado State University, Fort Collins, Colorado.

[47] A. Girard, "Influence des Propriétés Optiques du Revêtement d'une Sphère sur la Pression de Radiation," Rech. Aerosp, no. 1978-4, Muitre de Recherche a l'ONERA., pp. 209-212, 1978.

[48] G. Duchossois, "Potential European climatological satellite missions: SEOCS and BIRAMIS," Acta Astronautica, vol. 7, pp. 385--399, 1980.

[49] N.G. Loeb, S. Kato, and B. Wielicki, "Defining Top-of-theAtmosphere Flux Reference Level for Earth Radiation Budget Studies," Journal of Climate, vol. 15, no. 22, pp. 
3301--3309, 2002. DOI: 10.1175/15200442(2002)015<3301:DTOTAF>2.0.CO;2.

[50] G.B. Ohring, "Achieving satellite instrument calibration for climate change (ASIC)," pp. 142, 2007, NOAA.

[51] N. Fox, A. Kaisser-Weiss, W. Schmutz, K. Thome, D. Young, B. Wielicki, R. Winkler, and E. Woolliams, "Accurate radiometry from space: An essential tool for climate studies," Philos. Trans. Roy. Soc., vol. 369A, pp. 4028-4063, 2011. DOI: :10.1098/rsta.2011.0246.

[52] Global Climate Observing System, "The Global observing System for climate: Implementation needs," pp. 128, 2016, GCOS-200 (GOOS-214), WMO.

[53] Y. Boudon, F. Barlier, A. Bernard, R. Juillerat, A.M. Mainguy, and J.J. Walch, "Synthesis of flight results of the Cactus accelerometer for accelerations below $10^{-9} \mathrm{~g}$," Acta Astronautica, vol. 6, pp. 1387--1398, 1979.

[54] E.M. Gaposchkin, and A.J. Coster, "Analysis of Satellite Drag," The Lincoln Laboratory Journal, vol. 1, no. 2, pp. 203-224, 1988.

[55] G.E. Cook, "The effect of Aerodynamic Lift on Satellite Orbits," Planetary and Space Science, vol. 12, pp. 1009$1020,1964$.

[56] D.G. King-Hele, "Satellite Orbits in an atmosphere: Theory and application," 1987, Blackie and Son Ltd, Glasgow, UK.

[57] B.K. Ching, D.R. Hickman, J.M. Straus, "Effects of atmospheric winds and aerodynamic lift on the inclination of the orbit of the S3-1 satellite," JGR, vol. 82, no. 10, pp. 1474$1480,1977$.

[58] K. Moe, and B.R. Bowman, "The Effects of Surface Composition and Treatment On Drag Coefficients of Spherical Satellites," AAS/AIAA AstrodynamicsSpecialists Conference, Lake Tahoe, CA, August 2005.

[59] B.R. Bowman, and K. Moe, "Drag Coefficient Variability at 175-500 km from the Orbit Decay Analyses of Spheres," Advances in the Astronautical Sciences, vol. 123, pp. 117-130,2006

[60] G. Alfonso, F. Barlier, F. Mignard, M. Carpino, and P. Farinella," Orbital effects of LAGEOS seasons and eclipses," Annales Geophysicae, vol. 7, pp. 501-514, Oct. 1989.

[61] F. Mignard, G. Afonso, F. Barlier, M. Carpino, P. Farinella, A. Milani, and A. M. Nobili, "Lageos: Ten years of quest for the non-gravitational forces," Advances in Space Research, vol. 10 , no. 3, pp. 221--227, 1990. DOI: 10.1016/02731177(90)90352-Z.

[62] P. Poinas, "Satellite Thermal Control Engineering (prepared for "SME 2004")," European Space Agency, ESTEC, Thermal and Structure Division. T. Duhamel, T. and P. Marchai, "Earth Radiation Budget: Simulation of Fluxes and Accelerometric Measurements," 29th Congres International d'Astronautique - Section Etudiants, Dubrovnik, Yugoslavia,1-8 October 1978, pp. 15.

[63] A. Bernard, M. Gay, A.M. Mainguy, et al., "Radiation pressure determination with the CACTUS accelerometer," Space research, vol. XVIII, pp. 163 - 168, 1978.

[64] G.L. Stephens, G.G. Campbell, and T.H. Vonder Haar, "Earth radiation budgets," JGR, vol. 86, no. CIO 9739, 9760, October 1981.

[65] S. Kato, "Interannual variability of the global radiation budget," Journal of Climate, vol. 22, pp. 4893-4907, 2009.

[66] B.D. Tapley, S. Bettadpur, M. Watkins, C. Reigber, "The Gravity Recovery and Climate Experiment: Mission Overview and Early Results," GRL, vol. 31-9, no. L09607, 2004.

[67] A. Allasio, D. Muzi, B. Vinai, S. Cesare, G. Catastini, M. Bard, J. Marque, "GOCE: space technology for the reference earth gravity field determination," In: EUCASS 2009. Versailles, 2009.

[68] C. Reigber, P. Schwintzer, Lühr, "The CHAMP geopotential mission," Boll. Geof. Teor. Appl., vol. 40, pp. 285-289, 1999.

[69] F. Flechtner, P. Morton, M. Watkins, F. Webb, "Status of the GRACE Follow-on mission," In: Marti, U. (Ed.), Gravity, Geoid and Height Systems. Vol. 141 of International Association.
[70] B. Christophe, D. Boulanger, B. Foulon, P.-A. Huynh, V. Lebat, F. Liorzou, and E. Perrot, E., "A new generation of ultra-sensitive electrostatic accelerometers for GRACE Follow-on and towards the next generation gravity missions," Acta Astronautica, vol. 117, no. 17. 2015.

[71] V. Josselin, P. Touboul and R. Kielbasa, "Capacitive detection scheme for space accelerometers applications," Sensors and Actuation, vol. 78, pp. 92-98, 1999.

[72] P. Touboul, B. Foulon and E. Willemenot, "Electrostatic space accelerometers for present and future missions," Acta Astronautica, vol. 45-10, pp. 605-617, 1999.

[73] J. Bergé, B. Christophe, and B. Foulon, "GOCE accelerometers data revisited: stability and detector noise," Proceeding of ESA Living Planet Symposium 2013, Edinburgh, UK, 9-13 September 2013 (ESA SP-722, December 2013).

[74] B. Lenoir, A. Lévy, B. Foulon, B. Lamine, B. Christophe, and S. Reynaud, "Electrostatic accelerometer with bias rejection for Gravitation and Solar System physics," $A d v$. Space Res. vol. 48, no. 7, pp. 1248-1257, 2011.

[75] B. Lenoir, B. Christophe, and S. Reynaud, "Unbiased acceleration measurements with an electrostatic accelerometer on a rotating platform," Advances in Space Research, vol. 51, pp. 188-197, 2013.

[76] C. Pardini, E.K. Tobiska, and L. Anselmo, "Analysis of the orbital decay of spherical satellites using different solar flux proxies and atmospheric density models," Advances in Space Research, vol. 37, no. 2, pp. 392-400, 2006. DOI: 10.1016/j.asr.2004.10.009.

[77] F. Barlier, F. Mignard, M. Carpino, P. Farinella, and A. Milani, "Nongravitational perturbations on the semimajor axis of LAGEOS," Annales Geophysicae, vol. 4, pp. 193-$210,1986$.

[78] J. Lee Jasper, and K. Kemble, "Drag and Atmospheric Neutral Density Explorer (DANDE) - Spherical Spacecraft Design Challenges," March 31, 2009, CoSGC Symposium.

[79] M.D. Pilinski, and S.E. Palo, "An Innovative Method for Measuring Drag on Small Satellites," Proceedings of the 23nd Annual AIAA/USU Conference on Small Satellites, Logan, UT, USA, Aug. 10-13, 2009, SSC09-VIII3.

[80] H. M. Jones, I. I. Shapiro, P. E. Zadunaisky, H. C. Van De Hulst, C. De Jager, and A. F. Moore, "Solar Radiation Pressure Effects, Gas Leakage Rates, and Air Densities Inferred From the Orbit Of Echo I". Space Research II, Proceedings of the Second International Space Science Symposium, Florence, April 10-14, 1961.

[81] E.F. Harrison, and D.R. Brooks, "Mission analysis to define satellite orbits for Earth radiation budget measurements," AIAA/AAS Astrodynamics Conference, San Diego, CA, August 1976.

[82] M.L. Salby, "Asynoptic Sampling Considerations for WideField-of-View measurements of outgoing radiation. Part II: Dirunal and Random space-time variability," Journal of the Atmospheric Sciences, vol. 45, no. 7, pp. 1184-1204.

[83] P.C. Taylor, and N.G. Loeb, "Impact of Sun-Synchronous diurnal sampling on tropical TOA flux interannual variability and trends," Journal of Climate, vol. 26, pp. 2184-2191, 201.

[84] Gristey, J. J., J. C. Chiu, R. J. Gurney, S.-C. Han, and C. J. Morcrette (2017), Determination of global Earth outgoing radiation at high temporal resolution using a theoretical constellation of satellites, J. Geophys. Res. Atmos., 122, 1114-1131, doi:10.1002/2016JD025514.

[85] B. A. Wielicki et al., "CLARREO Pathfinder Mission: Enabling Faster Observation of Climate Change," American Geophysical Union, Fall Meeting 2015, abstract \#GC32C01.

[86] J.L. Chen, C.R. Wilson, B.D. Tapley,"Contribution of ice sheet and mountain glacier melt to recent sea level rise," Nature Geoscience, vol. 6, pp. 549-552, 2013, doi:10.1038/ngeo1829. 


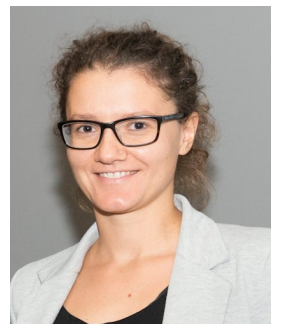

Maria Z. Hakuba, born in Poland in 1984, received her bachelor's (2008), master's (2011) and Ph.D. (2015) degrees in environmental sciences from the Federal Institute of Technology, Zurich, Switzerland. Currently, she is a postdoctoral Fellow with Colorado State University, Ft Collins, working at the Jet Propulsion Laboratory in Pasadena, California. She studies Earth's energy balance and water cycle exploring surface, satellite and climate model datasets.

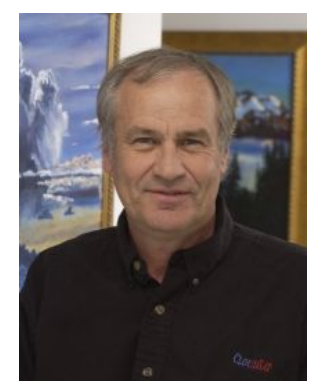

Graeme L. Stephens was born 1952 in Ballarat Victoria, Australia. He received his $\mathrm{PhD}$ in Meteorology from University of Melbourne in 1977. He was appointed to the CSIRO Division of Atmospheric Research in 1977 as a research scientist and promoted to senior research scientist in 1982. Dr. Stephens joined the Department of Atmospheric Science, Colorado State University, as an associate professor in 1984 and was promoted to full professor in 1991 and to the rank of University Distinguished Professor in 2005. He has served as principal investigator for the NASA CloudSat mission and currently serves as co-Chair of the Scientific Steering Group for the Global Energy and Water Exchanges (GEWEX) project of the WCRP. Prof. Stephens has received a number of awards in recognition of his contributions. Most recently he was elected as member of the U.S. National Academy of Engineering in 2016 and elected as Fellow of the Royal Society in 2018.

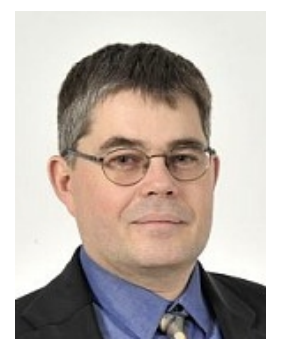

Bruno Christophe graduated from ISAE/SupAéro Engineering school in 1990. He joined ONERA in the Syntheses Study Direction in 1990. In 2000, he joined the Physics and Instrumentation Department at ONERA for GOCE accelerometer development, as Technical Manager. Since 2011, he is the head of Instrumentation and Aerospace Equipment, involved in the space accelerometer development and project manager of the GRACE-FO accelerometer. He is a member of the CNES advisory group for fundamental physics since 2011 .

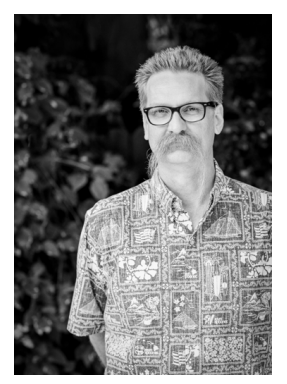

Alfred Nash received his B.S. in Physics from Stanford University (1986), and his $\mathrm{PhD}$ in Physics from U.C. Santa Barbara (1991). After working as a lecturer and postdoctoral researcher, he joined the Jet Propulsion Laboratory in 1994. At the Jet Propulsion Laboratory he has been involved in the development of test facilities and flight hardware for SIRTF/Spitzer, Planck, and the Orbiting Carbon Observatory. He is currently the Lead Engineer of Team X, the Jet Propulsion Laboratory's advanced design team for rapidly generating innovative space mission concepts.

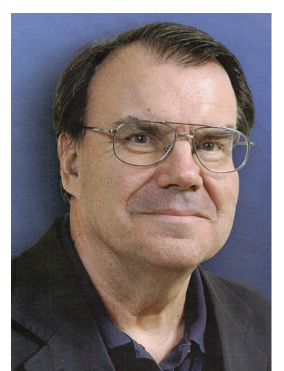

Born in Paris, France, in 1949, Bernard Foulon has a PhD in electronics, metrology and instrumentation from University Pierre et Marie Curie (Paris VI - 1979). Since 1979 until his retirement in July 2016, he was a research engineer at ONERA, the French Aerospace Lab. He is an expert in capacitive metrology and ultrasensitive electrostatic accelerometers for space applications with more than fifty publications in the field. He is presently Emeritus member of ONERA and adviser of the Director of the Physics Instrumentation Environment and Space Department. Dr. Foulon received the great prize of the French Air and Space Academy in 2010 for its contribution to the CHAMP, GRACE and GOCE missions.

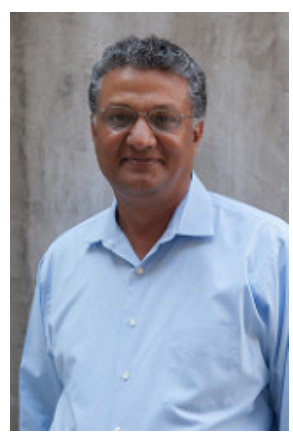

Srinivas Bettadpur is the Director of the University of Texas Center for Space Research, and is an Associate Professor in the Department of Aerospace Engineering and Engineering Mechanics. His areas of specialization include orbital mechanics, astrodynamics, orbit determination, satellite geodesy, and related mission design and mission architecture development. He is a fellow of the IAG and an Associate Fellow of the AIAA. He obtained his $\mathrm{PhD}$ in Aerospace Engineering from The University of Texas at Austin in 1993.

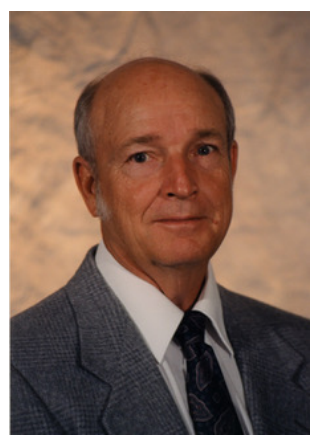

Byron D. Tapley is Clare Cockrell Williams Chair Emeritus at the University of Texas Austin and Director Emeritus of the Center for Space Research. His research interests include orbit mechanics, nonlinear parameter estimation and the application of satellite data to study Earth System dynamical interactions. $\mathrm{He}$ is the Principal Investigator for the GRACE Mission; whose goal is to observe mass exchange within and between the Earth System Components. He is a member of the NAE, a fellow of the AIAA, AGU and AAAS. Awards he has received include the NASA Medal for Exceptional Scientific Achievement, NASA Exceptional Public Service Medal, AAS Brouwer Award, AIAA Mechanics and Control of Flight Award and AGU Charles A. Whitten Medal. He served as a member of the NRC $\mathrm{SSB}$ and $A S E B$, and has Chaired the NRC SSB Committee on Earth Studies. He has served as a member of the NASA Advisory Committee, Vice Chair of the NASA NAC Science Committee and on numerous NASA and other government advisory panels, including the Science Steering Groups for SEASAT, TOPEX, EOS, and LAGEOS. 


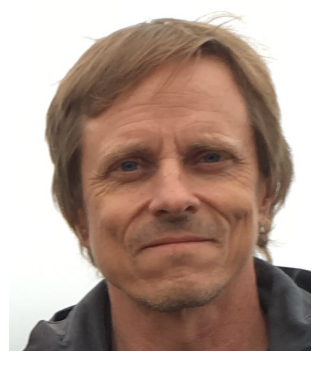

Frank Webb is the Project Scientist for Gravity Recovery and Climate Experiment Follow-on (GRACE-FO) and the Deputy Manager for the Earth Science Research and Mission Formulation Office at NASA's Jet Propulsion Laboratory (JPL). Dr. Webb received the B.A. degree in Geology from University of California, Santa Barbara, and the M.S. and Ph.D. degrees in Geological Sciences from California Institute of Technology. He has been a principal investigator on a number of research projects sponsored by NASA, is Chief Scientist for NASA Space Geodesy Program, and has been a member of the project teams for NASA's Shuttle Radar Topography Mission (SRTM) and Gravity Recovery and Interior Laboratory (GRAIL). Dr. Webb has chaired a number of planning and steering committees for NASA and the National Science Foundation for solid Earth and space geodesy research activities and projects. He has been the recipient of several awards including, along with his colleagues, the Space Foundation Space Technology Hall of Fame for precise GPS positioning. 